\title{
PEER EFFECTS IN THE ADOPTION OF A YOUTH EMPLOYMENT SUBSIDY
}

\author{
Claudio A. Mora-García
}

Tomás Rau

\section{LATIN AMERICAN AND THE CARIBBEAN ECONOMIC ASSOCIATION}

October 2018

The views expressed herein are those of the authors and do not necessarily reflect the views of the Latin American and the Caribbean Economic Association. Research published in this series may include views on policy, but LACEA takes no institutional policy positions.

LACEA working papers are circulated for discussion and comment purposes. Citation of such a paper should account for its provisional character. A revised version may be available directly from the author.

(C) 2018 by Claudio A. Mora-García and Tomás Rau. All rights reserved. Short sections of text, not to exceed two paragraphs, may be quoted without explicit permission provided that full credit, including (C) notice, is given to the source. 
LACEA WORKING PAPER SERIES No. 0015 October 2018

Peer Effects in the Adoption of a Youth Employment Subsidy

Claudio A. Mora-García

Universidad de Costa Rica

claudio.mora@ucr.ac.cr

Tomás Rau

Instituto de Economía, Pontificia Universidad Católica de Chile

trau@uc.cl

\begin{abstract}
This paper studies the effects of peers in the adoption of a Youth Employment Subsidy in Chile since its inception. We study the effects that former classmates' and coworkers' adoption has on one's adoption. Identification comes from discontinuities in the assignment rule that allow us to construct valid instrumental variables for peers' adoption. Using a comprehensive set of administrative records, we find that classmates and, especially, coworkers play a significant role in the adoption of the subsidy. Peer effects are determined during the early stages of the program's implementation and vary by network characteristics and the strength of network ties.
\end{abstract}

JEL Classification: H53, I38, C31

Keywords: Peer effects; subsidy adoption; partial population approach.

\title{
ACKNOWLEDGEMENTS AND FINANCIAL DISCLOSURE
}

We would like to thank Leonardo Bursztyn, Gordon Dahl, Jeanne Lafortune, John Giles, and seminar participants at CEDE Universidad de los Andes (Bogotá), SOLE (Raleigh), IAAE (Sapporo), Jobs and Development Conference (World Bank), LACEA (Medellín), SECHI (Viña del Mar), Universidad de Chile, Pontificia Universidad Católica de Chile, and Pontificia Universidad Javeriana (Colombia) for valuable comments. We also thank Cristián Crespo and Nicolás Andrade from the Ministerio de Desarrollo Social, and Andrea López from SENCE for facilitating data access. Bernardo de Moura provided invaluable research assistance. The usual disclaimer applies. Tomás Rau acknowledges the funding provided by Fondecyt, Project No. 1171128. Powered@ NLHPC: This research was partially supported by the supercomputing infrastructure of the NLHPC (ECM-02) 


\section{Introduction}

The role of social interactions on individuals' decisions has been increasingly studied in the last decade. By interacting with others, we gain information and absorb different opinions, which may shape our own decisions. In particular, social interactions may play an important role in the take-up of government social programs. Peers could serve as a source of information transmission about the costs and benefits of a program, as noted by Dahl, Løken and Mogstad (2014), "particularly in settings where information is scarce and perceptions are in their formative stage."

However, empiricists have had difficulties studying social interactions, mainly because of econometric hurdles, such as the reflection problem, correlated unobservables, and endogenous group membership (Manski, 1993; Moffitt, 2001; Graham and Hahn, 2005; Blume et al., 2015). Despite these problems, recent econometric developments have ignited a new wave of empirical research on peer effects. In particular, a series of papers uses instrumental variables and a method known as the "partial population" approach to estimate how another's behavior affects one's decisions (Moffitt, 2001). ${ }^{1}$ In such an approach, program eligibility is randomly assigned to a subset of peers and not correlated with unobservable factors that might affect adoption. This random variation, along with other conditions discussed below, helps to overcome the identification issues described above.

In this paper, we study the role of peer effects on the take-up of the Youth Employment Subsidy (YES) program in Chile since its inception. This program was launched in 2009 to increase the labor market participation of young people from low-income families. To do so, it complements the wages of under 25 , low-income individuals by up to $20 \%$ and awards the employer a bonus of up to $10 \%$ of an employee's wage. This is a significant cash incentive for

\footnotetext{
${ }^{1}$ See, for example, Joensen and Nielsen (2018); Rege, Telle and Votruba (2012); Robalino and Pfaff (2012); Monstad, Propper and Salvanes (2011); Bobonis and Finan (2009); Maurin and Moschion (2009); Figlio (2007); Munshi (2003).
} 
vulnerable youths to enter the labor market and for firms to employ them. However, the takeup of the YES program is low. ${ }^{2}$ With less than $20 \%$ of those eligible applying and millions of dollars going unclaimed, one has to wonder, why is so much cash left on the table? There is a host of reasons that nearly $80 \%$ of those eligible may not be applying to receive the YES. Perhaps they (mistakenly) believe they are ineligible; they might not know enough about the program's benefits or believe that the cost of applying is prohibitive. Another potential factor preventing people from applying is social stigma associated with this program since it explicitly targets low-income families. However, information about the program (or the lack thereof) is likely an important factor determining whether Chileans ultimately benefit from this subsidy. ${ }^{3}$

To consistently estimate the peer effects of the YES program, we follow a partial population approach that addresses the aforementioned identification issues. In particular, we exploit discontinuities in the program's eligibility criteria that allow us to construct credible instrumental variables for peer adoption in the following way. In March 2009, when the Chilean government announced that it was about to implement this employment benefit, with a predetermined set of eligibility criteria, some people fell onto the eligible side of the criteria, while others landed on the ineligible side. Specifically, some people met the age criterion (below 25 years of age), and the income criterion (bellow CLP $\$ 360,000$ per month), while others did not. Hence, there exists a small neighborhood or "window" around these thresholds where eligibility is as-if randomly assigned. Using this quasi-random variation

\footnotetext{
${ }^{2}$ Despite the launch of a promotional campaign for the program in 2009, the take-up rate was only $3.6 \%$ for employers and approximately $21 \%$ for employees, according to Bravo and Rau (2012). The campaign consisted of field visits by the Minister and a team from the Ministry of Labor and Social Welfare. It was complemented with advertising placed on national television, regional radio, national and local newspapers, subways and public transportation in Santiago, and bus stops (Huneeus, 2010).

${ }^{3}$ Wage subsidies suffer from particularly low take-up rates, even when compared with other social programs. Impact evaluations of such subsidies in Turkey, Austria, Belgium, Jordan, and the U.S. support this claim (see Almeida, Orr and Robalino, 2014, for an overview). The main reasons proposed for the low adoption of this type of program are the complexity or high costs of learning and application (Aizer, 2007; Bitler, Currie and Scholz, 2003; Currie et al., 2001; Dahan and Nisan, 2011; Daly and Burkhauser, 2003) and stigma (Moffitt, 1983). Furthermore, limited benefits from applying (Anderson and Meyer, 1997; Riphahn, 2001) and behavioral issues related to the profile of the payments, such as time-inconsistency and present bias, have also been suggested as explanations (O'Donoghue and Rabin, 1999).
} 
in program eligibility for a subset of peers, we construct plausible exogenous instrumental variables for peers' adoption as the share of eligible peers inside the neighborhood around the eligibility threshold. This allows us to identify peer effects in program participation among eligible workers whose networks contain individuals in such a window.

To determine how peers may affect one's take-up of this employment benefit, we examine two social networks: coworkers and former high school classmates. People who are eligible for the YES program but have yet to apply may learn about the program, its benefits, and the application process from coworkers. This communication plays a central role in the dissemination and take-up of the YES employment benefit. ${ }^{4}$ Because the YES program targets young workers, it is possible that friendship networks developed during high school may also impact information acquisition about the program and, by extension, take-up. Analyzing the effects of different networks is interesting since we do not know a priori which is the relevant peer group. To the best of our knowledge, this is the first paper in the take-up literature to study the effect of classmates on the adoption of a social program.

We have access to rich linked employer-employee and student-school data that allow us to identify coworkers and former high school classmates and to construct different types of networks for a given individual. An advantage of the dataset is that we can use networks formed before the introduction of YES, thereby alleviating concerns regarding the endogenous group membership issue. This is not possible in other contexts where a social program has been in operation for several years because groups' composition before the program started could no longer be relevant. Furthermore, peers and peer group composition could have endogenously adapted to stigma or social program participation in general, thereby biasing the estimates. Since we analyze networks created before the introduction of YES, any changes

\footnotetext{
${ }^{4}$ For example, in referral-based models, coworkers provide information about available jobs and the unobserved productivity of workers (Glitz, 2017). Dahl, Løken and Mogstad (2014) also find significant peer effects among coworkers in social program participation.
} 
in group formation will be arguably exogenous to the introduction of YES.

Our results support that individuals learn about YES from one another and that this communication plays a role in disseminating the program, especially during the early months of its implementation. While a 10 percent increase in the fraction of former classmates adopting the subsidy increases the probability of own's adoption by 1.1 percentage points (pp), a 10 percent increase in the fraction of coworkers taking up the program increases the likelihood of own adoption by $2.9 \mathrm{pp}$. The results are robust to a variety of control variables.

We find suggestive evidence favoring an informational channel as a candidate for explaining the results. Peer effects are higher in networks characterized by strong ties, measured by those including coworkers that had been working at the same firm for a more extended period. This result may be expected since working with peers for a more extended period increases the likelihood of interaction and the diffusion of information about the program. Finally, the effect of peers on subsidy adoption is mostly determined in the first two years of program implementation.

The remainder of the paper is organized as follows. Section II describes the YES program, and Section III describes the various sources of administrative records. Section IV explains the identification strategy and estimation methods, and Section V presents the results. Section VI discusses the main findings and possible mechanisms, and Section VII concludes the paper.

\section{Institutional Background}

The YES program was launched in July 2009. It is a two-fold monetary incentive targeted at workers in the 18-24 age range belonging to the poorest 40 percent of the population, according to a proxy means index called the Ficha de Protección Social (FPS, hereafter). ${ }^{5}$

\footnotetext{
${ }^{5}$ The FPS is a proxy means index used for targeting social programs that ranges from 2,072 to 16,316 points, with a higher number implying a lower degree of vulnerability. An FPS score less than or equal to 11,734 means that a household is in the lowest 40th percentile of the distribution.
} 
The YES program incorporates wage bonuses for employees and employers. However, the application processes are independent, and workers and employers must apply separately through an online system.

Eligibility Criteria. A worker is admissible if she

1) has a gross annual income less than $\operatorname{CLP} \$ 4,320,000$ (US\$8,640) or a gross monthly wage less than CLP $\$ 360,000(\mathrm{US} \$ 720){ }^{6}$

2) is between 18 and 24 years old;

3) has an FPS score equal to or less than 11,734 points, corresponding to the poorest 40 percent;

4) is not working in a state institution or a firm with a state contribution higher than $50 \%^{7}$; and

5) have social security contributions paid up to date.

Application. The YES application process differs from those of many social programs that use complex procedures to avoid rejecting deserving candidates or awarding the subsidy to ineligible ones (Kleven and Kopczuk, 2011). Instead, it is simple and can be completed at any time, from any place, over the internet. ${ }^{8}$ This online application process considerably reduces the necessary paperwork and simplifies several procedures. For example, documents

\footnotetext{
${ }^{6}$ According to the law, all quantities in Chilean pesos are adjusted each year for the annual variation experienced by the Chilean Consumer Price Index.

${ }^{7}$ The AFC database only includes private firms and not public firms. In Chile, firms for which the state has a stake exceeding $50 \%$ are defined as state-owned enterprises (SOEs). SOEs also include firms created by law, those of which the state is the owner or those for which the state appoints most members of its board. According to the Chilean Securities and Insurance Supervisor (SVS), there are only 34 SOEs, the names of which can be found at http://www.svs.cl/educa/600/w3-propertyvalue-1066.html, and they employed a total of 40,239 persons during 2014, of all ages and socioeconomic conditions. Moreover, according to the Third Chilean Longitudinal Firm Survey conducted in 2013 , only 22 of the 7,267 surveyed firms (0.3\%) had a state contribution in excess of $50 \%$. For this reason, the empirical strategy will not consider this point.

${ }^{8}$ Workers and employers' applications must be submitted at the website www.subsidioempleojoven.cl. Once the worker's ID number is entered, the system immediately reports whether the requirements have been met. In a favorable case, a simple and brief registration form will then have to be completed and submitted. The application status can be verified at any time by accessing the YES website. If the website refuses the application option on the grounds of an FPS score higher than the cutoff score, the worker can approach his municipality and ask for his FPS score to be recalculated. However, this does not guarantee that the FPS score will be updated.
} 
establishing the working relationship are verified internally, and documentation for medical licensing is also internally audited by the Social Security Institute (IPS). ${ }^{9}$ This implies that complexity or high application costs are not a plausible explanation for the program's low take-up rate (Aizer, 2007; Bitler, Currie and Scholz, 2003; Blasco and Fontaine, 2009; Currie et al., 2001; Dahan and Nisan, 2011; Daly and Burkhauser, 2003).

Payments. If the worker's application is approved, the bonus (up to $20 \%$ of the wage) is paid in one installment in the second half of the next calendar year (annually paid by default). However, the worker may opt for monthly payments that begin to be paid within a maximum period of 90 days after application. ${ }^{10}$ Hence, the waiting period between application and first payment is relatively brief, and a behavioral explanation (time-inconsistency bias) for low take-up rates should not apply in this case (O’Donoghue and Rabin, 1999).

In both cases (annual or monthly payments), the subsidy is distributed through the payment method chosen by the employee: cash or a bank deposit. This means that the payments are private information that is difficult for colleagues to obtain unless a YES recipient explicitly discloses receiving the bonus. The privacy of payments makes stigma less likely to be a factor explaining the low take-up rate of the program (Moffitt, 1983; Riphahn, 2001; Bursztyn, Egorov and Jensen, Forthcoming).

For employers, the subsidy (up to $10 \%$ of the wage) is paid in monthly installments that begin within a maximum period of 90 days from the date of submission, in the form of a direct deposit into a checking account (it is not a tax credit).

Finally, the level of the YES benefit is significant, which makes less plausible the argument that low benefit levels are responsible for the low adoption rate in this program (Anderson and Meyer, 1997; Riphahn, 2001). Table 1 displays the amount of the subsidy

\footnotetext{
${ }^{9}$ Paperwork is necessary in very specific cases, but in these cases, the required documentation may be electronically uploaded to the website.

${ }^{10}$ According to Bravo and Rau (2012), in the 2009-2010 period, approximately two-thirds of the YES beneficiaries opted for monthly payments.
} 
entitled to eligible workers in a phase-in, plateau, and phase-out manner, in 2009. For employers, the amount of the subsidy is simply half of that in Table 1.

End of Payments. The benefit is retained as long as the recipient continues to meet the above criteria. Beginning in April 2011, a worker who is 21 years or older must have obtained a high school diploma to access or continue receiving the subsidy. Subsidy payments cease during months in which the worker's employer fails to pay her social security contributions (or pays late), and they then resume when contributions are again up-to-date. ${ }^{11}$

\section{Data}

\section{A. Various sources of administrative records}

We have access to four different administrative datasets that can be merged by using a unique identification number (ID): FPS, Unemployment Insurance (AFC), Chilean Student Registration (RECH), and the YES.

The FPS database includes the individual's date of birth, sex, educational level, municipality of residence, an indicator for whether the person was born in Chile and the FPS (proxy means) score.

The AFC database contains matched employer-employee data with information on all the workers who have ever contributed to the Chilean unemployment insurance (UI) system since it was introduced in October 2002. These are formal, dependent, employed workers from the private sector (not the public sector - see footnote 7). It includes information on each employee's total taxable income, social security contributions, and the number of months with taxable income in the last six and 12 months.

At the time the data were delivered to us by the Ministry of Social Planning, the AFC

\footnotetext{
${ }^{11}$ Two particular groups of workers have the right to request additional time to access YES: (i) workers who have completed regular studies in a higher education institution and (ii) mothers, who may request an extension for each child born alive within three months of her 25 th birthday.
} 
database was already merged with the FPS dataset. This "FPS+AFC" database provides information on unemployed individuals and on workers and their firm of employment before and after the YES program began. It allows us to determine whether a worker meets YES eligibility criteria, the labor network of formal dependent workers, individual and mean peer characteristics, and characteristics at the employer level. We have access to a panel from December 2007 to September 2013 with a periodicity of March, September, and December.

The RECH database contains information on the academic history of students enrolled at primary and secondary educational institutions (other than higher education) between 2002 and 2012. The variables include a school ID where the student is registered, grades, and classroom codes. The RECH database allows for exact identification of the classmates at different educational institutions, years and grades. For further details, see Abarca et al. (2005).

Regarding the program, the YES database contains administrative lists of all payments from 2009 to 2012. It contains an indicator of monthly or annual payment and the month and year of the subsidy. This database allows us to determine when a worker began to receive YES and whether at any time $t$ the worker is receiving YES.Once the unique individual identifiers are used to merge the data, we obtain a sample of 394,668 individuals. The estimating samples vary from 90,668 to 197,238 observations due to eligibility requirements, network definitions, and missing values. In Tables A1 and A2, we report descriptive statistics for the entire sample and three different estimating samples. 


\section{Empirical Strategy}

\section{A. A partial population solution to the reflection problem}

As in Dahl, Løken and Mogstad (2014), assume that groups have only two peers and that there is random eligibility for individuals with the label $1, z_{1 g} \in\{0,1\}$, while for individuals with the label 2 there is no such a variation, being all eligible for the program. Let $y_{i g}$ be the outcome for individual $i$ in group $g, x_{i g}$ individual's $i$ covariates, and $\varepsilon_{i g}$ a residual term. Thus, we can write the system of simultaneous equations for peer effects as

$$
\begin{aligned}
& y_{1 g}=\alpha_{1}+\eta_{1} x_{1 g}+\beta_{1} y_{2 g}+\gamma_{1} x_{2 g}+\delta z_{1 g}+\varepsilon_{1 g}, \\
& y_{2 g}=\alpha_{2}+\eta_{2} x_{2 g}+\beta y_{1 g}+\gamma_{2} x_{1 g}+\varepsilon_{2 g} .
\end{aligned}
$$

As discussed by Dahl, Løken and Mogstad (2014), since $z_{1 g}$ is random, it is orthogonal to observed and unobserved covariates, and correlated unobservables can no longer bias the estimates. The exclusion of $z_{1 g}$ from equation (2) solves the reflection problem, as long as individual 2 make their choice after individuals type 1 , and $\beta$ is identified. Also, if peer groups are measured before the introduction of the program, endogenous group membership does not bias the peer effect estimator. Then, we can rewrite equations (1) and (2) as follows

$$
\begin{aligned}
& y_{1 g}=\alpha_{1}+\eta_{1} x_{1 g}+\gamma_{1} x_{2 g}+\delta z_{1 g}+\varepsilon_{1 g}, \\
& y_{2 g}=\alpha_{2}+\beta y_{1 g}+\eta_{2} x_{2 g}+\gamma_{2} x_{1 g}+\varepsilon_{2 g},
\end{aligned}
$$

where equation (3) uses the fact that individual 2 make their choice after individual 1 , so $y_{2 g}$ does not affect $y_{1 g}$. Now, as in a linear-in-means model, when groups have more than two individuals the take-up decision may be affected by average behavior of peers in the 
group. Exploiting the random eligibility of type 1 individuals, we focus on the effect of average behavior of type 1 individuals on type 2 ones. Thus, taking averages respect to type 1 individuals in equations (3) and (4), we obtain the following system of equations

$$
\begin{aligned}
& \bar{y}_{1 g}=\alpha_{1}+\eta_{1} \bar{x}_{1 g}+\gamma_{1} x_{2 g}+\delta \bar{z}_{1 g}+\varepsilon_{1 g}, \\
& y_{2 g}=\alpha_{2}+\beta \bar{y}_{1 g}+\eta_{2} x_{2 g}+\gamma_{2} \bar{x}_{1 g}+\varepsilon_{2 g},
\end{aligned}
$$

and the resulting reduced-form model is given by

$$
y_{2 g}=\left(\alpha_{2}+\beta \alpha_{1}\right)+\left(\eta_{2}+\beta \gamma_{1}\right) x_{2 g}+\left(\gamma_{2}+\beta \eta_{1}\right) \bar{x}_{1 g}+\delta \beta \bar{z}_{1 g}+v_{2 g},
$$

which implies that $\delta$ can be consistently estimated by regressing $\bar{y}_{1 g}$ on $\bar{z}_{1 g}$ (equation 5 ) and $\beta$ can be estimated by regressing $y_{2 g}$ on $\bar{z}_{1 g}$ (equation 7 ) and scaling by $\hat{\delta}$.

Our approach differs from Dahl, Løken and Mogstad (2014) in the number of type 1 peers in each network and the estimation approach. While they use networks with only one individual type 1 and are able to get regression discontinuity estimates of peer effects, we use networks with one or more individuals type 1 . Thus, we assess the effect of the average behavior of peers type 1 on type 2's adoptions in a two-stage least square strategy (2SLS). We follow this approach since we do not have enough power when restricting our sample to networks with only one type 1 peer.

\section{B. Quasi-random eligibility}

As discussed in section II, eligibility to the program changes sharply due to discontinuities in the assignment rule-eligible workers must have a monthly wage below CLP $\$ 360 \mathrm{~K}$ and be on the 18-24 age range. Figure 1 shows mean take-up rates by wage and age. As can bee 
seen, take-up jumps sharply at each threshold: $\$ 360,000$ and 25 years old respectively.

We argue that discontinuities in the YES assignment rule provide random variation within a narrow window around the eligibility thresholds. While individuals making slightly less than CLP $\$ 360 \mathrm{~K}$ a month are eligible for the program, individuals making slightly more are not. The same applies to age: individuals slightly younger than 25 years old are eligible, and those slightly older are not. Indeed, small differences in peer ages can be thought of as random, or at least the agent's decision of whether to apply for the YES program can be thought of as independent of any small differences in peer ages.

Note that the program was announced in March 2009 and implementation began in July of the same year, meaning that agents' income and work decisions made before 2009 cannot be a function of this program. That is, before 2009, agents could not finely manipulate their earnings as a function of the YES program, because the program did not exist. As such, if we consider a period before 2009, there exists an income interval around threshold $t$ where an individual's placement within that interval is quasi-randomly assigned. Based on this, we build a window of size $2 \Delta$ around the threshold eligibility wage, and we then calculate the percentage of agent $i$ 's peers that are eligible, inside the window. If more peers are on the eligible side, then more peers will potentially benefit from the program, and agent $i$ will be more likely to receive information about the program.

Since we have two discontinuities inducing random variation in eligibility, we construct two instruments for peers' adoption: a "wage" and an "age" instrument. To build the wage instrument, let us define $\mathcal{N}_{-i, g}$ as the set of $i^{\prime} s$ peers, in a given group $g$, that have a gross monthly income within the $2 \Delta$ window around the threshold (type- 1 individuals). Then, the 
share of agent $i$ 's peers on the eligible side of the threshold can be written as

$$
\bar{z}_{1 g}=\frac{1}{n_{g}} \sum_{j \in \mathcal{N}_{-i, g}} \mathbf{1}\left[\text { wage }_{j} \leq 360\right]
$$

where $n_{g}$ is the cardinality of set $\mathcal{N}_{-i, g}$, and $\mathbf{1}[\cdot]$ is an indicator function. Thus, $\bar{z}_{1 g}$ is simply the share of peers inside the $2 \Delta$ window who make CLP $\$ 360 \mathrm{~K}$ or less. ${ }^{12}$ We proceed in the same way to construct the age instrument. In that case, $\bar{z}_{1 g}=\frac{1}{n_{g}} \sum_{j \in \mathcal{N}_{-i, g}} \mathbf{1}\left[a g e_{j} \leq 25\right]$.

Figure 2 depicts the construction of the instrumental variable using wage (in CLP thousands). We plot a real line for wages with three cutoff points. Individuals to the left of $\$ 360-\Delta$ are eligible (type-2 individuals). The quasi-random eligibility $\left(z_{1 g} \in\{0,1\}\right)$ occurs in a narrow window defined by the closed interval $[360-\Delta, 360+\Delta]$, where $2 \Delta$ is the window size. Type- 1 individuals (inside the window) are eligible only if their wages are below $\$ 360$ (A), and those whose wages are larger than $\$ 360$ are not $(\mathrm{B})$. The instrumental variable is the fraction of eligible peers inside the window $(\mathrm{A} /(\mathrm{A}+\mathrm{B}))$. Individuals to the right of $\$ 360+\Delta$ are not used in the analysis.

\section{Network definitions and working sample}

We study two kinds of reference groups, coworkers, and classmates. The literature has provided extensive evidence on the importance of peer coworkers in one's decision making. For example, Glitz (2017) shows that coworker-based networks increase the probability of re-employment in Germany after a layoff. Related to the adoption of social programs, Dahl, Løken and Mogstad (2014) find that coworkers (and family members) positively affect paid paternity leave participation in Norway.

On the other hand, this is the first paper, to the best of our knowledge, to study the

\footnotetext{
${ }^{12}$ If agent $i$ has no peers within the window, the instrument has a missing value, and we follow a casewise deletion procedure. In that case, agent $i$ is not in the working sample.
} 
role of (former) classmates in the adoption of a social program. This may be particularly important since there is some evidence that classmates may affect labor market outcomes. In Chile, Zimmerman (2016) finds that admission to a selective college program raises the number of leadership positions that students hold at firms by $44 \%$, although gains are more significant for those who attended elite private high schools and negligible for students who did not. There is also evidence for Norway that peer composition in ninth grade, as measured by the proportion of females in the class, affects long-run outcomes, such as education and labor market outcomes (Black, Devereux and Salvanes, 2013).

Studying a social program since the beginning of its implementation has one particular advantage. We can use networks formed before the announcement of the program. In this case, endogenous group membership should not create bias since changes in group membership that occur after the introduction of the program are orthogonal to changes in $z_{i g}^{1}$.

When constructing the coworker network, we proceed as follows. For any individual with wage $<360-\Delta$ and age $<25-\Delta$ (type-2 individuals) we define his/her reference group as all coworkers during December 2008 whose wages or ages were within the small window previously defined (type-1 individuals). We choose this date because it is the closest date available in our sample to the YES announcement (March 2009). ${ }^{13}$

On the other hand, when constructing the classmate network, we define its reference group as all former classmates in eleventh and twelfth grades whose wages were within the aforementioned small window. ${ }^{14}$ Finally, the window width in our baseline estimation is 300 days for the age instrument (similar to Dahl, Løken and Mogstad (2014)) and CLP \$70K for the wage instrument. With these window widths, we obtain estimating samples of 90,668 to 197,238 individuals with at least one peer inside the "window". The average network sizes

\footnotetext{
${ }^{13}$ Age was measured in July 2009 - the month YES started-using the date of birth.

${ }^{14}$ Note that they are not only schoolmates but same-grade classmates. 
vary from 3.8 to 4.8 peers (see Appendix Tables A1 and A2 for details). In Section V, we present results with different window sizes and alternative network definitions as robustness checks.

\section{Results}

\section{A. Assessing the validity of the identification assumptions}

Our identification strategy assumes that in a small neighborhood around the assignment variable cutoffs (wage and age), eligibility is as good as random. Thus, as in a regression discontinuity design, identification fails if individuals perfectly manipulate the assignment variable (McCrary, 2008; Lee and Lemieux, 2010).

In Figure 3, we present the densities of wages and ages in December 2008 to assess whether individuals manipulate this variable to access the program. The results show a smooth density function for wages, Panel A, and ages, Panel B, at their respective cutoff points. In Appendix A1, we show densities for other dates and other measures of wages.

Moreover, as in any instrumental variable approach, the validity of the instrument depends on the absence of correlation between the error term and the instruments themselves (clean instruments). Hence, the instruments operate through a single known causal channel and induce random assignment throughout the population. In Appendix Table A3 we present the results of linear regressions of a variety of characteristics at the classmate and coworker levels on both instrumental variables (separately) to assess whether they are correlated. The results show that most of the coefficients are small and nonsignificant.

\section{B. Main results}

Table 2 shows the primary results using the two instruments. We focus on the effect of peers who adopt the subsidy in 2009 on individuals' adoption in the subsequent years 
(2010-2012) to reduce the incidence of the reflection problem. The set of covariates used and the network's construction determined based on pre-treatment information (December 2008). To avoid correlated unobservables, we use a wide range of covariates. All regressions include as control variables age, age ${ }^{2}$, sex, FPS score, $\ln$ (wage), and years of education. They also include peer characteristics, such as mean age, the fraction of women, mean vulnerability score, and average years of education. Standard errors are clustered at the group level.

We implement the estimation separately for the wage (Panel A) and the age (Panel B) instruments. Column (1) shows first-stage estimates, and as can be seen, there is a strong relationship between $y_{1 g}$ and $\bar{z}_{1 g}$ using both instruments, with F-statistics above 22 for the wage instrument and above 171 for the age instrument. Note that when using the age instrument, we only focus on the coworker network since we do not have enough variation in the instrument for the classmate network (classmates have nearly the same age). The estimates show that having a 10 pp higher fraction of eligible coworkers increased adoption by between 0.45 and $0.49 \mathrm{pp}$, and a $10 \mathrm{pp}$ higher fraction of classmates increased adoption in 2009 by $0.79 \mathrm{pp}$. These effects are statistically significant at the $1 \%$ level.

Column (2) shows the reduced-form estimates. This column shows that a worker is between 0.11 and $0.15 \mathrm{pp}$ more likely to adopt YES if he or she has a $10 \mathrm{pp}$ higher fraction of eligible coworkers and $0.09 \mathrm{pp}$ more likely if he or she has a $10 \mathrm{pp}$ higher fraction of eligible classmates. These effects are statistically significant at the $5 \%$ and $10 \%$ levels, respectively.

Finally, column (3) shows the 2SLS estimates. These coefficients measure the average causal peer effect of coworker and classmate adoption on individual adoption. Workers with a 10 pp higher fraction of coworkers with YES are 2.43-2.97 pp more likely to adopt YES, and those with a $10 \mathrm{pp}$ higher fraction of classmates with YES are $1.18 \mathrm{pp}$ more likely to adopt the subsidy.

While the context differs, our point estimates for coworker networks (0.29 pp) are be- 
tween those found by Dahl, Løken and Mogstad (2014) and Bobonis and Finan (2009). In a neighborhood context regarding peer effects in secondary school enrollment decisions, Bobonis and Finan (2009) find IV estimates of peer effects of approximately $0.5 \mathrm{pp}$. In a parental leave reform context, Dahl, Løken and Mogstad (2014) report coworker peer effects on take-up equal to $0.11 \mathrm{pp}$ and family peer effects of approximately $0.15 \mathrm{pp}$.

\section{Robustness checks}

Table 3 summarizes the robustness of our results to different specifications. We implement three different specifications. First, we estimate the model without control covariates. Then, we add a vector of individual covariates, and finally, we estimate a specification with individual and group covariates. ${ }^{15}$ Panel A shows the results for the coworker and classmate networks using the wage instrument. The results are overall robust to the three specifications and consistent with those reported in Table 2. In particular, we observe a significant first stage (at the 1\% level) in column (1) and significant reduced-form and second-stage estimates (between the 1\% and 10\% levels) in columns (2) and (3), respectively. The overall effect ranges from 0.28 to 0.31 in the coworker network. When using the classmate network, the effects range from 0.11 to 0.46 .

Panel B shows the same specifications as those in Panel A but using the age instrument. As column (1) shows, the first stage is statistically significant at the $1 \%$ level for the three specifications as in Panel A. The reduced-form and second-stage estimates, columns (2) and (3), are significant (at between the 1\% and 5\% levels), with 2SLS estimates ranging from 0.24 to 0.35. These results are consistent with those using the wage instrument (Panel A).

Figures 4 and 5 provide a sensitivity analysis of the results using different window sizes for the instruments. Figure 4 shows that the results are robust to different window sizes

\footnotetext{
${ }^{15}$ Other robustness checks performed considered municipality of residence fixed effects (to avoid correlated unobservables) and alternative definitions of worker wage. The results are consistent with those of our preferred specification.
} 
of the wage instrument for the coworker and classmate networks, and Figure 5 shows the sensitivity of the results to different window sizes of the age instrument. The results are robust to different age windows.

Finally, in Appendixes A2 and A3, we provide placebo estimates of the peer effects using different cutoff points for the wage and age eligibility rules. The results show that moving the cutoff points from their actual values decreases the estimated peer effects to close to zero.

In what follows, we analyze other aspects of the peer effects using the coworker network only. The main reason for this approach is that for the coworker network, we have the two instruments, while for the classmate network, we only have the age instrument since we do not have enough variation in age for classmates. Moreover, as displayed in Tables 2 and 3 , the results for the coworker network are more stable accross different specifications than those from the classmate network.

\section{Dynamics}

As discussed in Subsection V.B, thus far, we have reported the effects of peer adoption in 2009 on individual adoption in the subsequent years (2010-2012). To analyze the dynamics of the adoption process, we present the effects of peer adoption in 2009 on individual adoption within different time frames. In particular, we study the effect of peers adopting in 2009 on individual adoption in 2010, 2010-2011, and 2010-2012. To do so, for every period, we identify new adopters and assess the cumulative effect of peer adoption in 2009 on individual adoption.

Table 4 shows the evolution of the estimated peer effect for the coworker network. As Panels $\mathrm{A}$ and $\mathrm{B}$ show, the peer effect exhibits an increasing pattern but at a decreasing rate. Regardless of the instrument used (wage or age), the effects of early adopters (in 2009) on new adopters are sizable and significant, ranging from 0.16 to $0.26 \mathrm{pp}$ in the year after the 
implementation of the program (2010). These figures are close to the estimates for the entire period (2010-2012), suggesting that the long-term effect of peers is mostly determined during the early stages of program implementation.

\section{Discussion and Possible Mechanisms}

\section{A. Potential mechanisms}

The results in Section V show significant peer effects in the adoption of the program. In this context, peer effects are likely due to information transmission that translate into adoption. One potential mechanism is the program's initial information campaign. However, knowledge about the existence of the YES program would not automatically translate into adoption if the application procedure, admissibility rules, and other details were not understood. For example, during November 2014, the Minister of Labor conducted a media campaign encouraging the 122,000 YES beneficiaries to claim US\$ 37,029,382 unclaimed payments. The accumulation of unclaimed payments is sometimes due to unfamiliarity with how YES works. ${ }^{16}$ Unclaimed payments for some individual cases summed up to US $\$ 2,067 .{ }^{17}$ In total, during November 2014, 1,800 young adult workers could have claimed amounts in excess of US\$ $1,378 .^{18}$

A natural mechanism explaining our results is "social learning" (Bursztyn et al., 2014). Peers learn about the benefits and costs of program participation from one another. In this setting, the initial information set regarding the benefits and costs of participation was limited since it was an incipient program. Thus, the information transmission among peers may play a key role in program participation, especially during the first months of program implemen-

\footnotetext{
${ }^{16}$ As explained above, a person does not lose the benefit when he/she changes jobs, but the payments are held until he/she becomes eligible again, at which point payments resume automatically.

17 "Bono Trabajo Mujer y Subsidio al Empleo Joven: llaman a cobrar más de 21 mil millones", 24horas.cl, November 3, 2014; and "Ministra de Trabajo llama a cobrar bonos Trabajo Mujer y Empleo Joven", 24horas.cl, November 2, 2014.

18 "Bonos y subsidios Sence: llaman a cobrar $\$ 21$ mil millones no reclamados", 24horas.cl, October 24, 2014.
} 
tation. An indirect test of this hypothesis is to examine the first-stage results. As discussed previously, the admissibility requirements allowed some networks to have more/fewer eligible peers in a small window around the cutoff. The results show that the fraction of (arguably random) admissible peers increases individual adoption. This suggests that learning through the exchange of information is a plausible channel. However, the type of information transmitted may vary by a network's characteristics and the strength of its ties.

Hence, we first assess the presence of heterogeneous effects in two network dimensions: experience and age of peers. Older or more experienced peers may be more aware of the subsidy, its benefits, and the application process, and thus, the quality of information transmitted through this network may have differential impacts compared to that from networks with younger peers. Thus, we first define two networks: one with peers with five years or more of labor market experience and another with peers older than 20 years. Table 5 shows the results.

Panel A shows that older peers have a larger point estimate for the peer effect on subsidy adoption than the baseline estimates in the coworker network (0.36 vs. 0.30). Nevertheless, the difference between the two estimates is not statistically significant (at the $5 \%$ level). When using the age instrument, the point estimates are lower for networks with coworkers older than 20 years, but as in the previous case, the differences are not statistically significant (at the $5 \%$ level).

Following the literature on peer effects on educational outcomes (Lavy and Schlosser, 2011; Black, Devereux and Salvanes, 2013), we test for heterogeneous effects by sex composition of the labor force within firms. As in the education literature, we find that peer effects are larger in firms with a larger proportion of female workers. ${ }^{19}$

\footnotetext{
${ }^{19}$ Among the mechanisms analyzed, Lavy and Schlosser (2011) find that the presence of a higher proportion of girls decreases the level of disruption and violence in the classroom and improves relationships, not only among students but also teacher-students relationships.
} 
Finally, we examine peer effects among firms in which over $15 \%$ (the median) of workers are attending or graduated from vocational (técnico-profesional) secondary education. According to Larrañaga, Dussaillant and Cabezas (2014) and OEI (1993), the main objective of vocational secondary education in Chile is to promote successful transitions to the labor market through training in job skills in a given educational field or speciality. Vocational secondary education is more oriented than academic (científico-humanista) or artistic (artística) secondary education toward constructing abilities that help students find a job quickly after graduating. According to Larrañaga, Dussaillant and Cabezas (2014), students from vocational high schools have lower enrollment rates in higher education, higher occupation rates in the labor market (Bucarey and Urzúa, 2013), and higher wages during the early stages of their working life than students from academic high schools. See also Farías and Sevilla (2015) and de Iraurrizaga (2009). As a result, peer effects among students graduating from vocational high schools should be higher. This is precisely what we find.

\section{B. Networks with weaker and stronger ties}

Table 6 presents evidence on the sensitivity of the peer effects to networks with weaker and stronger ties using both instruments: wage and age. First, we consider peer effects among "former" coworkers defined as the person's coworkers in December 2007 (one year before the baseline definitions), which is expected to be a weak-tie network since it is likely that they are no longer coworkers (due to the high turnover rate in the Chilean labor market) and may have lost contact and thus the ability to share information. As Panels A and B show, the peer effect in this weak-tie network is nonsignificant for the wage instrument, and the point estimate is approximately $50 \%$ of that from the baseline specification (the network constructed with coworkers in December 2008). For the age instrument, the point estimate is similar to that of the baseline specification but significant at $10 \%$ only. Hence, the results 
are overall weaker in this weak-tie network for both instruments.

Then, we construct an alternative network that includes an individual's coworkers between March 2008 and December 2008, which we call "longer term coworkers." These are expected to be strong-tie networks compared to baseline one and, as Panels A and B of Table 6 show, they are statistically significant at the $1 \%$ and $5 \%$ levels for the wage and age instruments, respectively, and the point estimates are larger than those in the weak-tie network and similar to that of the baseline specification.

\section{Conclusions}

This paper estimates the effect of peers on the adoption of a Youth Employment Subsidy (YES) in Chile. We follow an instrumental variable approach by exploiting the exogenous variation in eligibility induced by discontinuities in the assignment rule. To address endogenous group membership, we use networks constructed with pre-program information, and as a result, all changes in the groups' composition are likely to be orthogonal to the introduction of the YES.

The results show that coworkers and classmates play a crucial role in determining participation in the program. A 10 pp higher fraction of coworkers with YES implies a 2.9 pp higher individual probability of adopting YES; a 10 pp larger fraction of classmates with YES increases the individual probability of adopting the program by $1.2 \mathrm{pp}$. The results are robust to different specifications and mostly determined during the early stages of the program implementation.

We present suggestive evidence favoring an informational channel driving our results. Peer effects vary by network characteristics and the strength of network ties. In particular, peer effects are larger in networks with older youths, in those with a higher share of female workers, and in those with highly technical workers. 
Finally, our results have significant implications for public policy. Not only coworkers but also classmates may play a significant role in information transmission regarding labor market policies for youth, especially for new programs in which information is scarce. 


\section{REFERENCES}

Abarca, María, J. M. Barrios, Jorge Del Río, and J. Serrano. 2005. "Registro de los Estudiantes de Chile: un sistema de información masiva en extranet." 369-374.

Aizer, Anna. 2007. "Public Health Insurance, Program Take-Up, and Child Health." Review of Economics and Statistics, 89(3): 400-415.

Almeida, Rita, Larry Orr, and David Robalino. 2014. "Wage subsidies in developing countries as a tool to build human capital: design and implementation issues." IZA Journal of Labor Policy, 3(1): 12.

Anderson, Patricia M., and Bruce D. Meyer. 1997. "Unemployment Insurance Takeup Rates and the After-Tax Value of Benefits." The Quarterly Journal of Economics, 112(3): 913-937.

Bitler, Marianne P., Janet Currie, and John Karl Scholz. 2003. "WIC Eligibility and Participation." The Journal of Human Resources, 38(May): 1139.

Black, Sandra E., Paul J. Devereux, and Kjell G. Salvanes. 2013. "Under Pressure? The Effect of Peers on Outcomes of Young Adults." Journal of Labor Economics, 31(1): 119-153.

Blasco, Sylvie, and François Fontaine. 2009. "A structural model of the unemployment insurance take-up." Université du Main.

Blume, Lawrence E., William A. Brock, Steven N. Durlauf, and Rajshri Jayaraman. 2015. "Linear Social Interactions Models." Journal of Political Economy, 123(2): 444-496. 
Bobonis, Gustavo J., and Frederico Finan. 2009. "Neighborhood Peer Effects in Secondary School Enrollment Decisions." Review of Economics and Statistics, 91(4): 695-716.

Bravo, David, and Tomás Rau. 2012. "Effects of Large-scale Youth Employment Subsidies: Evidence from a Regression Discontinuity Design."

Bucarey, Alonso, and Sergio Urzúa. 2013. "El retorno económico de la educación media técnico profesional en Chile." Estudios, 129(verano): 3-48.

Bursztyn, Leonardo, Florian Ederer, Bruno Ferman, and Noam Yuchtman. 2014. "Understanding Mechanisms Underlying Peer Effects:Evidence From a Field Experiment on Financial Decisions." Econometrica, 82(4): 1273-1301.

Bursztyn, Leonardo, Georgy Egorov, and Robert Jensen. Forthcoming. "Cool to Be Smart or Smart to Be Cool? Understanding Peer Pressure in Education." Review of Economic Studies.

Currie, Janet, Jeffrey Grogger, Gary Burtles, and Robert F. Schoeni. 2001. "Explaining Recent Declines in Food Stamp Program Participation." Brookings-Wharton Papers on Urban Affairs, 2001(1): 203-244.

Dahan, Momi, and Udi Nisan. 2011. "Explaining Non-Take-up of Water Subsidy." Water, 3(4): 1174-1196.

Dahl, Gordon B., Katrine V. Løken, and Magne Mogstad. 2014. "Peer effects in program participation." American Economic Review, 104(7): 2049-2074.

Daly, Mary C, and Richard V Burkhauser. 2003. "The Supplemental Security." In Means-Tested Transfer Programs in the United States. Vol. I, , ed. Robert A. Moffitt, Chapter 2, 79-139. University of Chicago Press. 
de Iraurrizaga, Francisca. 2009. "Dos miaradas a la educación media en Chile." PhD diss. Pontificia Universidad Católica de Chile.

Farías, Mauricio, and María Paola Sevilla. 2015. "Effectiveness of Vocational High Schools in Students' Access to and Persistence in Postsecondary Vocational Education." Research in Higher Education, 56(7): 693-718.

Figlio, David N. 2007. "Boys Named Sue: Disruptive Children and Their Peers." Education Finance and Policy, 2(4): 376-394.

Glitz, Albrecht. 2017. "Coworker networks in the labour market." Labour Economics, 44: $218-230$.

Graham, Bryan S., and Jinyong Hahn. 2005. "Identification and estimation of the linear-in-means model of social interactions." Economics Letters, 88(1): $1-6$.

Huneeus, Cristóbal. 2010. "Balance de los avances y desafíos de las políticas de empleo para jóvenes." Proyecto PREJAL, Santiago de Chile.

Joensen, Juanna Schrøter, and Helena Skyt Nielsen. 2018. "Spillovers in education choice." Journal of Public Economics, 157: 158 - 183.

Kleven, Henrik Jacobsen, and Wojciech Kopczuk. 2011. "Transfer Program Complexity and the Take-Up of Social Benefits." American Economic Journal: Economic Policy, 3(1): 54-90.

Larrañaga, Osvaldo, L. Francisca Dussaillant, and Gustavo Cabezas. 2014. "Trayectorias educacionales e inserción laboral en la enseñanza media técnico profesional." Estudios Públicos, 134(otoño): 7-58.

Lavy, Victor, and Analia Schlosser. 2011. "Mechanisms and Impacts of Gender Peer Effects at School." American Economic Journal: Applied Economics, 3(2): 1-33. 
Lee, David S, and Thomas Lemieux. 2010. "Regression Discontinuity Designs in Economics." Journal of Economic Literature, 48(2): 281-355.

Manski, Charles F. 1993. "Identification of Social Endogenous Effects: The Reflection Problem." The Review of Economic Studies, 60(3): 531-542.

Maurin, Eric, and Julie Moschion. 2009. "The Social Multiplier and Labor Market Participation of Mothers." American Economic Journal: Applied Economics, 1(1): 251272.

McCrary, Justin. 2008. "Manipulation of the running variable in the regression discontinuity design: A density test." Journal of Econometrics, 142: 698-714.

Moffitt, Robert A. 1983. "An economic model of welfare stigma." The American Economic Review, 73(5): 1023-1035.

Moffitt, Robert A. 2001. "Policy Interventions, Low-Level Equilibria, and Social Interactions." In Social Dynamics. , ed. Steven N Durlauf and Peyton Young, Chapter 3, 45-82. Cambridge, MA:MIT Press.

Monstad, Karin, Carol Propper, and Kjell G. Salvanes. 2011. "Is teenage motherhood contagious?" NHH Dept. of Economics Discussion Paper No. 12/2011.

Munshi, Kaivan. 2003. "Networks in the Modern Economy: Mexican Migrants in the U. S. Labor Market." The Quarterly Journal of Economics, 118(2): 549-599.

O'Donoghue, Ted, and Matthew Rabin. 1999. "Doing It Now or Later." American Economic Review, 89(1): 103-124.

OEI. 1993. Sistema Educativo Nacional de Chile. Santiago:http://www.oei.es/historico/quipu/chile/index.html\#sis. 
Rege, Mari, Kjetil Telle, and Mark Votruba. 2012. "Social Interaction Effects in Disability Pension Participation: Evidence from Plant Downsizing*." The Scandinavian Journal of Economics, 114(4): 1208-1239.

Riphahn, Rt. 2001. "Rational poverty or poor rationality? The take-up of social assistance benefits." Review of income and wealth, 1(3): 379-398.

Robalino, Juan A., and Alexander Pfaff. 2012. "Contagious development: Neighbor interactions in deforestation." Journal of Development Economics, 97(2): 427-436.

Zimmerman, Seth. 2016. "Making the One Percent: The Role of Elite Universities and Elite Peers." National Bureau of Economic Research, Cambridge, MA. 
Figure 1. : YES take-up by wage and age, 2010-2012

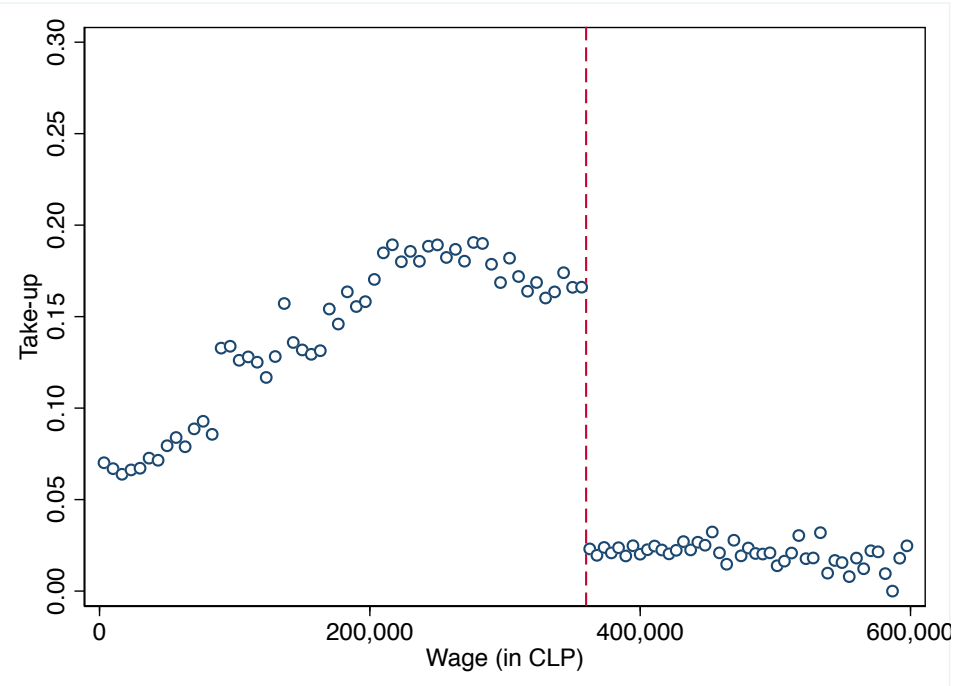

Panel A. Take-up by wage

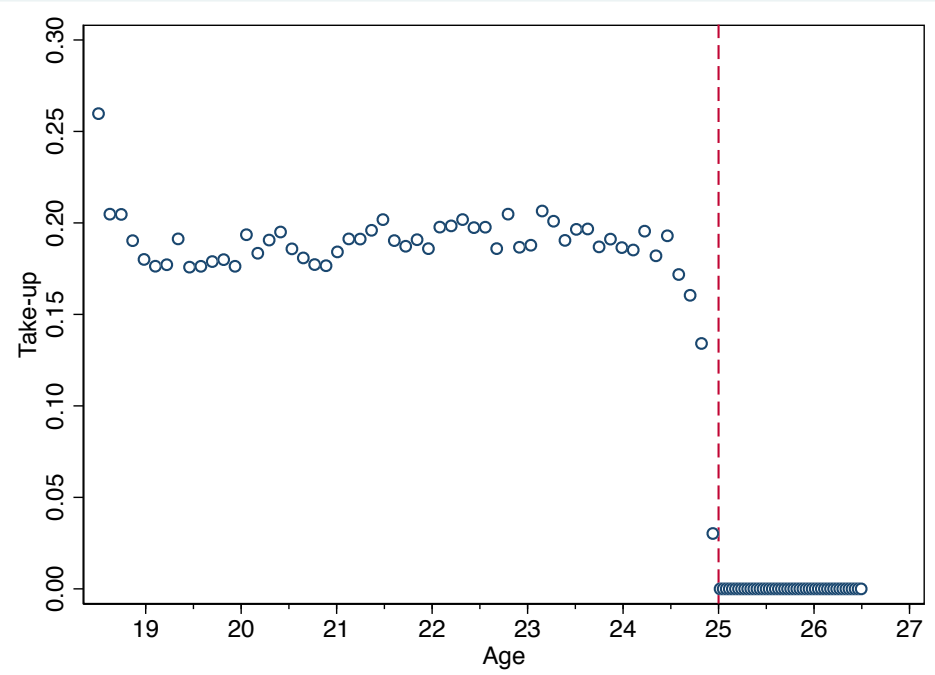

Panel B. Take-up by age

Notes: Panel A shows the take-up rate of the program by wage in CLP. Each dot shows the share of individuals taking up the subsidy in a given wage bin. The sample is restricted to youths between 18 and 25 years with a FPS score lower than 11,734. Panel B shows the take-up rate by age. Each dot shows the share of individuals taking the subsidy in a given age bin. The sample is restricted to workers earning less than CLP $\$ 360,000$ years and a FPS score lower than 11,734. The dashed vertical line in each panel denotes the eligibility cutoff according to the corresponding variable (wage and age). 
Figure 2. : Quasi-random eligibility using the wage criterion

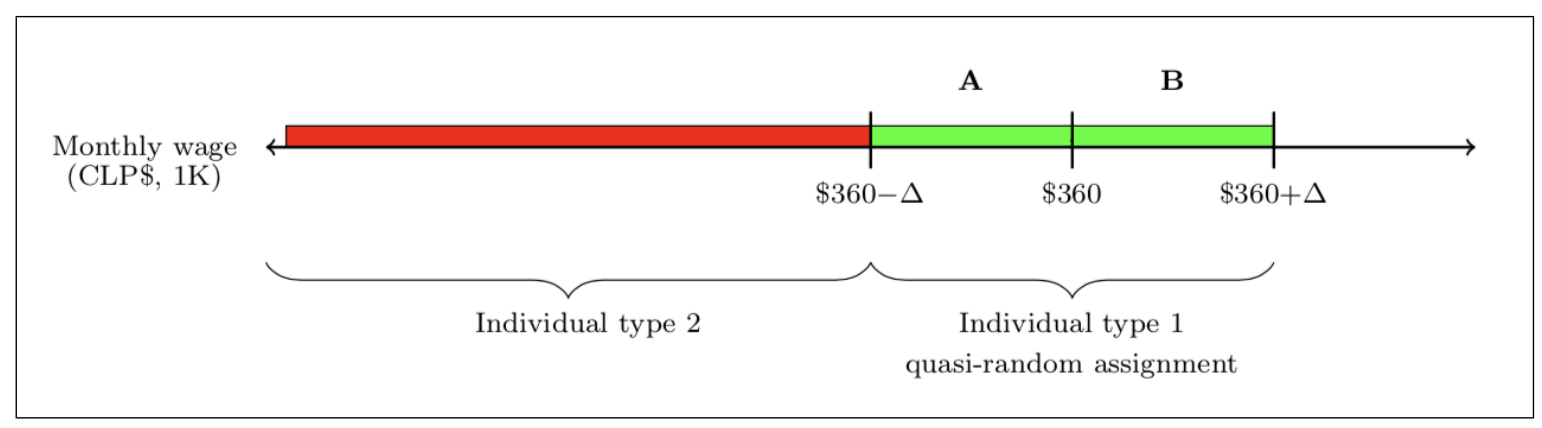

Notes: Individuals to the left of $\$ 360 \mathrm{~K}-\Delta$ are eligible individuals (type 2 ). The quasi-random eligibility occurs in a narrow window defined by the interval $[360 K-\Delta, 360 K+\Delta]$ where $\Delta$ is the window size. Type 1 peers inside the window are eligible only if their wages are below $\$ 360 \mathrm{~K}(\mathrm{~A})$ and those whose wages are larger than $\$ 360 \mathrm{~K}$ are not $(\mathrm{B})$. The instrumental variable is the fraction $A /(A+B)$. 
Figure 3. : Density Estimates of age and wages, December 2008

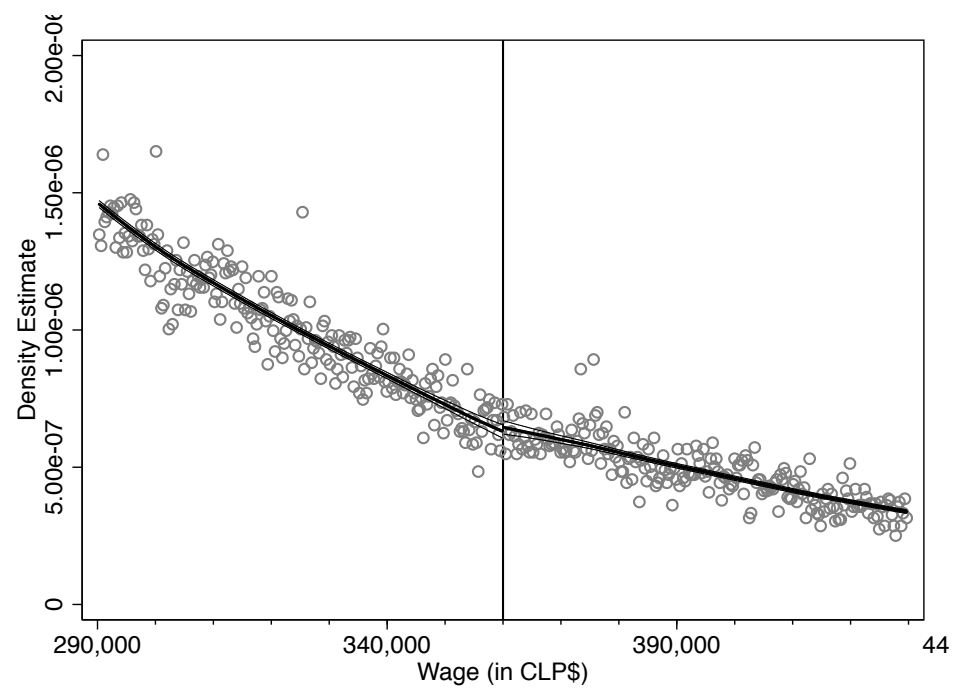

Panel A. Wage density

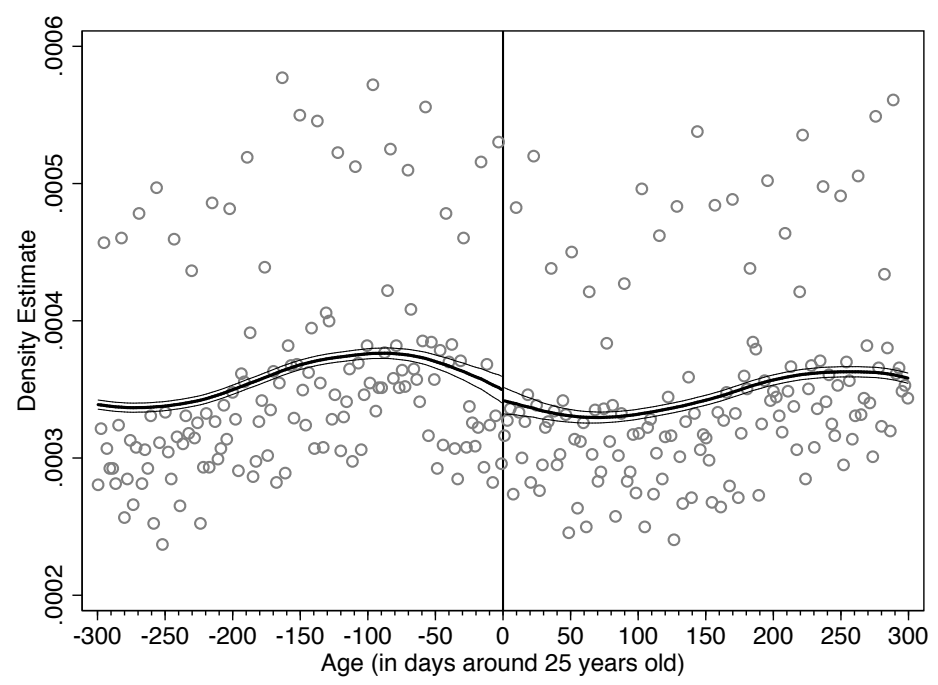

Panel B. Age density

Notes: Panel A shows the monthly wage density estimates. The dashed vertical line denote the eligibility cutoff of CLP $\$ 360,000$. Optimal bandwidth is CLP $\$ 36,267$. Panel B shows the age (in days) density estimates. The dashed vertical line denote the age cutoff of 25 , which has been normalized to zero. Optimal bandwidth is 123 days. 
Figure 4. : Sensitivity of peer effects to different window widths using the wage cutoff.

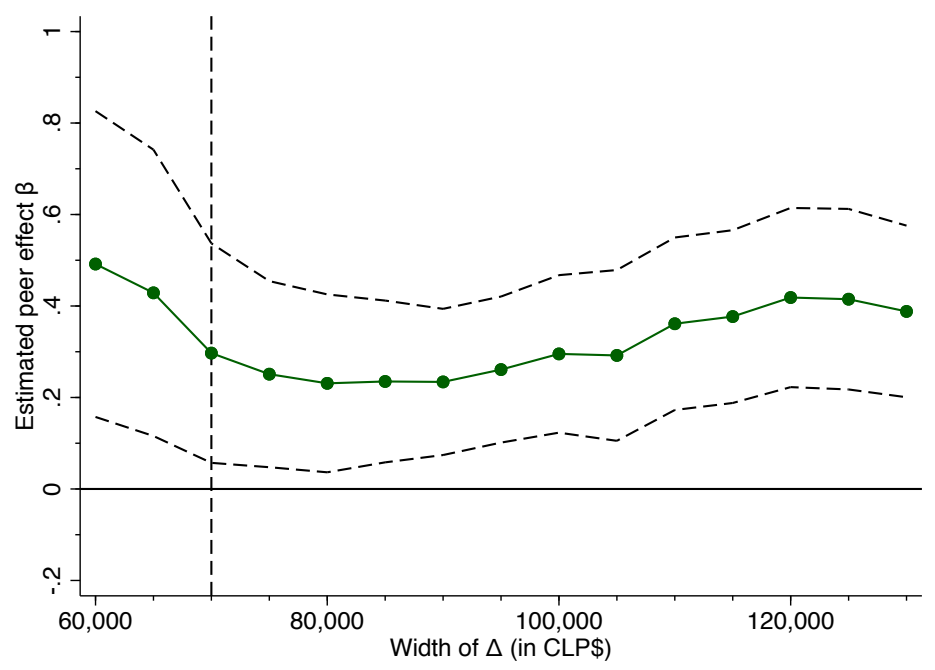

Panel A. Coworkers' networks

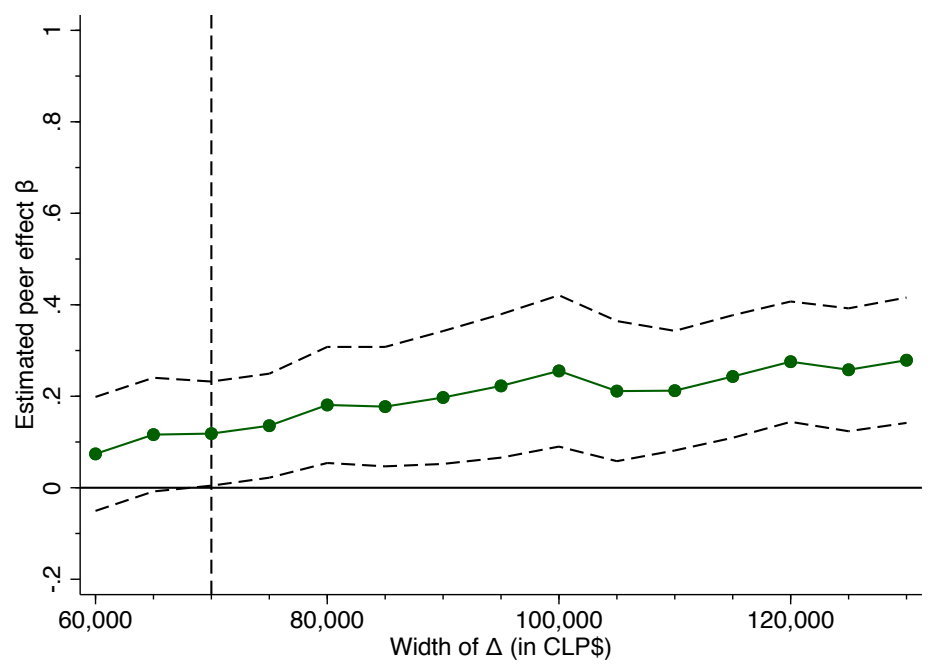

Panel B. Classmates' networks

Notes: Each dot on panels A and B represent the estimated peer effect $\beta$ from the single 2SLS equation (??) for the given window width shown in the horizontal axis. Each dot in Panel A represent the 2SLS coefficient at the coworkers network; while each dot in Panel B represent the 2SLS coefficient at the classmates network. All regressions use the specifications in Table 2. The dashed lines are the $95 \%$ confidence interval, with clustered standard errors at the group level. The vertical line shows our selected width of CLP $\$ 70,000$. 
Figure 5. : Sensitivity of peer effects to different window widths using the age cutoff.

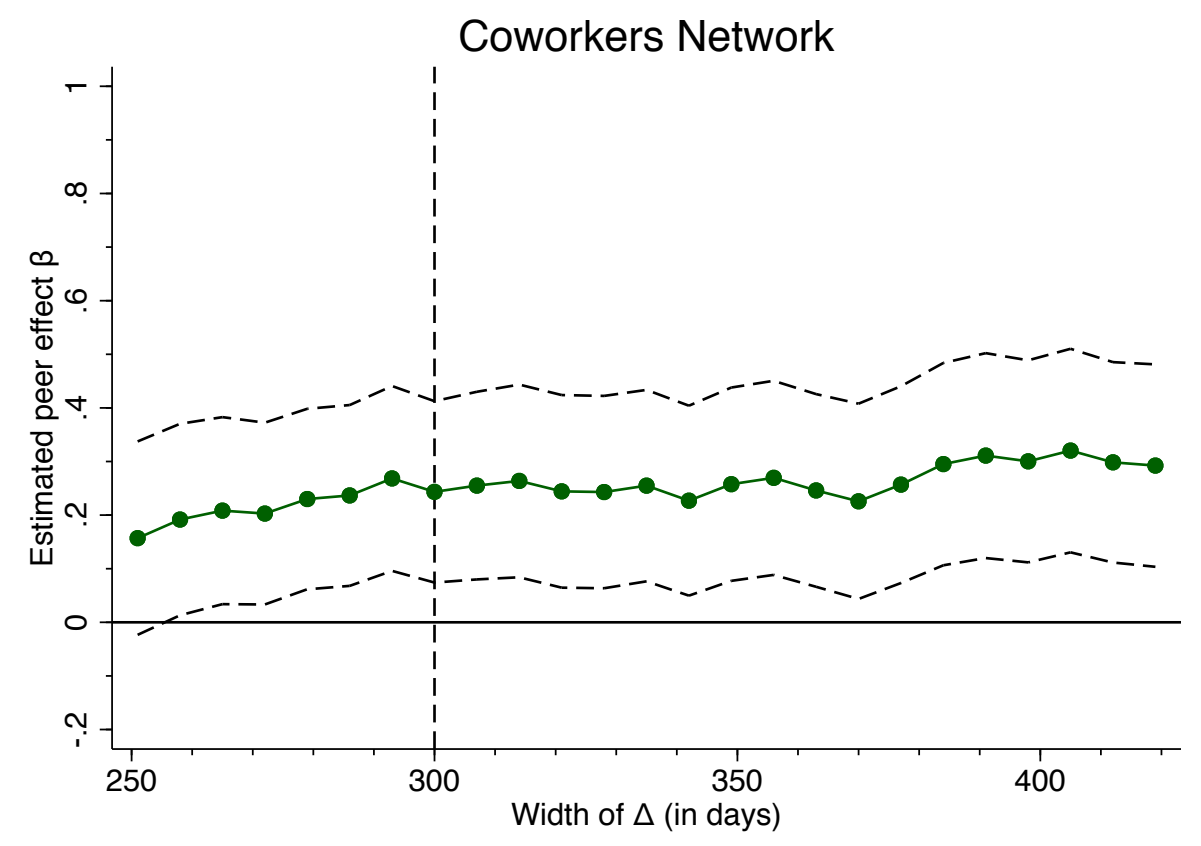

Notes: See Figure 4 for a description. Standard errors clustered at the group level. The vertical line shows our selected width of 300 days. 
Table 1-: Payment scheme for workers, by annual gross income and monthly gross income.

\begin{tabular}{|c|c|}
\hline Panel A Annual Gross Income (AI) & Subsidy (YES) \\
\hline $\mathrm{AI} \leq \$ 1,920,000$ & $0.2 \times(A I)$ \\
\hline$\$ 1,920<\mathrm{AI} \leq \$ 2,400,000$ & $\$ 384,000$ \\
\hline$\$ 2,400<\mathrm{AI} \leq \$ 4,320,000$ & $\$ 384,000-0.2 \times(A I-\$ 2,400,000)$ \\
\hline Panel B: Monthly Gross Income (MI) & Subsidy (YES) \\
\hline $\mathrm{MI} \leq \$ 160,000$ & $0.2 \times(M I)$ \\
\hline$\$ 160,000<\mathrm{MI} \leq \$ 200,000$ & $\$ 32,000$ \\
\hline$\$ 200,000<\mathrm{MI} \leq \$ 360,000$ & $\$ 32,000-0.2 \times(M I-\$ 200,000)$ \\
\hline
\end{tabular}

Notes: figures in CLP of 2009. 
Table 2-: Effect of peers' adoption in 2009 on YES adoption during 2010-2012.

\begin{tabular}{cccc}
\hline First Stage & Reduced Form & Second Stage & $N$ \\
$(1)$ & $(2)$ & $(3)$ & $(4)$ \\
\hline
\end{tabular}

Panel A. Wage instrument

$\begin{array}{ccccc}\text { 1. Coworkers } & 0.0487^{* * *} & 0.0145^{* *} & 0.2971^{* *} & 166,871 \\ & {[0.0104]} & {[0.0067]} & {[0.1459]} & \\ \text { F-statistic } & \text { 22.1 } & & & \\ & & & & \\ \text { 2. Classmates } & 0.0785^{* * *} & 0.0093^{*} & 0.1184^{*} & 90,668 \\ & {[0.0136]} & {[0.0054]} & {[0.0692]} & \\ \text { F-statistic } & 33.5 & & & \end{array}$

Panel B. Age instrument

$\begin{array}{ccccc}\text { 1. Coworkers } & 0.0450^{* * *} & 0.0109^{* *} & 0.2434^{* *} & 197,238 \\ \text { F-statistic } & {[0.0034]} & {[0.0046]} & {[0.1029]} & \end{array}$

Notes: Regressions include individual age, age squared, sex, vulnerability score, $\ln ($ wage $)$ and years of education as controls. They also include peers' characteristics (group controls), such as mean age, the fraction of women, mean vulnerability score, and average years of education. Column (1) shows first-stage coefficients and column (2) shows reducedform coefficients. Column (3) shows 2SLS coefficients. Adopters during 2010-2012 are those who received any YES payment between 2010 and 2012 only, and not during 2009. Panel A uses the wage instrument; while panel B uses the age instrument. Clustered standard errors at the group level in brackets: Significant at $* 10 \%, * * 5 \%, * * * 1 \%$. 
Table 3-: Robustness checks

\begin{tabular}{|c|c|c|c|c|}
\hline & $\begin{array}{c}\text { First Stage } \\
(1)\end{array}$ & $\begin{array}{c}\text { Reduced Form } \\
(2)\end{array}$ & $\begin{array}{c}\text { Second Stage } \\
(3)\end{array}$ & $\begin{array}{l}\mathrm{N} \\
(4)\end{array}$ \\
\hline \multicolumn{5}{|c|}{ Panel A. Wage instrument } \\
\hline \multicolumn{5}{|l|}{ A.1 Coworkers' network } \\
\hline 1. No controls & $\begin{array}{c}0.0566^{* * *} \\
{[0.0104]}\end{array}$ & $\begin{array}{c}0.0177^{* *} \\
{[0.0074]}\end{array}$ & $\begin{array}{c}0.3136^{* *} \\
{[0.1342]}\end{array}$ & 166,871 \\
\hline $\begin{array}{l}\text { 2. Individual } \\
\text { Controls }\end{array}$ & $\begin{array}{c}0.0563^{* * *} \\
{[0.0104]}\end{array}$ & $\begin{array}{c}0.0159^{* *} \\
{[0.0070]}\end{array}$ & $\begin{array}{c}0.2822^{* *} \\
{[0.1270]}\end{array}$ & 166,871 \\
\hline $\begin{array}{l}\text { 3. Invidividual }+ \text { Groups } \\
\text { Controls }\end{array}$ & $\begin{array}{c}0.0487^{* * *} \\
{[0.0104]}\end{array}$ & $\begin{array}{c}0.0145^{* *} \\
{[0.0067]}\end{array}$ & $\begin{array}{l}0.2971^{* *} \\
{[0.1459]}\end{array}$ & 166,871 \\
\hline \multicolumn{5}{|l|}{ A.2 Classmates' network } \\
\hline 1. No controls & $\begin{array}{c}0.0882^{* * *} \\
{[0.0138]}\end{array}$ & $\begin{array}{c}0.0411^{* * *} \\
{[0.0071]}\end{array}$ & $\begin{array}{c}0.4664^{* * *} \\
{[0.0989]}\end{array}$ & 90,668 \\
\hline $\begin{array}{l}\text { 2. Individual } \\
\text { Controls }\end{array}$ & $\begin{array}{c}0.0818^{* * *} \\
{[0.0138]}\end{array}$ & $\begin{array}{c}0.0110^{* *} \\
{[0.0055]}\end{array}$ & $\begin{array}{c}0.1345^{* *} \\
{[0.0677]}\end{array}$ & 90,668 \\
\hline $\begin{array}{l}\text { 3. Individual + Groups } \\
\text { Controls }\end{array}$ & $\begin{array}{c}0.0785^{* * *} \\
{[0.0136]}\end{array}$ & $\begin{array}{l}0.0093^{*} \\
{[0.0054]}\end{array}$ & $\begin{array}{l}0.1184^{*} \\
{[0.0692]}\end{array}$ & 90,668 \\
\hline \multicolumn{5}{|c|}{ Panel B. Age instrument } \\
\hline B.1 Coworkers' network & & & & \\
\hline 1. No controls & $\begin{array}{c}0.0453^{* * *} \\
{[0.0034]}\end{array}$ & $\begin{array}{c}0.0156^{* * *} \\
{[0.0051]}\end{array}$ & $\begin{array}{c}0.3458^{* * *} \\
{[0.1153]}\end{array}$ & 197,238 \\
\hline $\begin{array}{l}\text { 2. Individual } \\
\text { Controls }\end{array}$ & $\begin{array}{c}0.0452^{* * *} \\
{[0.0034]}\end{array}$ & $\begin{array}{c}0.0131^{* * *} \\
{[0.0047]}\end{array}$ & $\begin{array}{c}0.2887^{* * *} \\
{[0.1055]}\end{array}$ & 197,238 \\
\hline $\begin{array}{l}\text { 3. Individual }+ \text { Groups } \\
\text { Controls }\end{array}$ & $\begin{array}{c}0.0450^{* * *} \\
{[0.0034]}\end{array}$ & $\begin{array}{c}0.0109^{* *} \\
{[0.0046]}\end{array}$ & $\begin{array}{c}0.2434^{* *} \\
{[0.1029]}\end{array}$ & 197,238 \\
\hline
\end{tabular}

Notes: Regressions in this table mirror those in Table 2. Clustered standard errors at the group level in brackets: Significant at * $10 \%, * * 5 \%, * * * 1 \%$. 
Table 4-: Evolution of peer effects over time, coworkers network.

\begin{tabular}{cccc}
\hline First Stage & Reduced Form & Second Stage & N \\
$(1)$ & $(2)$ & $(3)$ & $(4)$ \\
\hline
\end{tabular}

Panel A. Wage instrument

$\begin{array}{lcccc}\text { 1. } 2010 & 0.0487^{* * *} & 0.0125^{* *} & 0.2572^{*} & 166,871 \\ & {[0.0104]} & {[0.0062]} & {[0.1327]} & \\ & & & & \\ \text { 2. } 2010-2011 & 0.0487^{* * *} & 0.0138^{* *} & 0.2839^{* *} & 166,871 \\ & {[0.0104]} & {[0.0065]} & {[0.1420]} & \\ & & & & \\ \text { 3. 2010-2012 } & 0.0487^{* * *} & 0.0145^{* *} & 0.2971^{* *} & 166,871 \\ & {[0.0104]} & {[0.0067]} & {[0.1459]} & \end{array}$

Panel B. Age instrument

$\begin{array}{lcccc}\text { 1. } 2010 & 0.0450^{* * *} & 0.0074^{* *} & 0.1644^{*} & 197,238 \\ & {[0.0034]} & {[0.0038]} & {[0.0842]} & \\ & & & & \\ \text { 2. } 2010-2011 & 0.0450^{* * *} & 0.0093^{* *} & 0.2069^{* *} & 197,238 \\ & {[0.0034]} & {[0.0045]} & {[0.1001]} & \\ & & & & \\ \text { 3. 2010-2012 } & 0.0450^{* * *} & 0.0109^{* *} & 0.2434^{* *} & 197,238 \\ & {[0.0034]} & {[0.0046]} & {[0.1029]} & \end{array}$

Notes: This table shows the effect of peers' adoption in 2009 on adoption in different time frames using the same specifications as those in Table 2. Clustered standard errors at the group level in brackets: Significant at $* 10 \%, * * 5 \%, * * * 1 \%$. 
Table 5-: Heterogeneous effects, coworker network

\begin{tabular}{|c|c|c|c|}
\hline & $\begin{array}{c}\text { First Stage } \\
(1)\end{array}$ & $\begin{array}{c}\text { Reduced Form } \\
(2)\end{array}$ & $\begin{array}{c}\text { Second Stage } \\
(3)\end{array}$ \\
\hline \multicolumn{4}{|c|}{ Panel A. Wage instrument } \\
\hline 1. Baseline & $\begin{array}{c}0.0487^{* * *} \\
{[0.0104]}\end{array}$ & $\begin{array}{c}0.0145^{* *} \\
{[0.0067]}\end{array}$ & $\begin{array}{c}0.2971^{* *} \\
{[0.1459]}\end{array}$ \\
\hline $\begin{array}{l}\text { 2. Over } 5 \text { years } \\
\text { of experience }\end{array}$ & $\begin{array}{c}0.0488^{* * *} \\
{[0.0103]}\end{array}$ & $\begin{array}{c}0.0151^{* *} \\
{[0.0067]}\end{array}$ & $\begin{array}{c}0.3085^{* *} \\
{[0.1471]}\end{array}$ \\
\hline 3. Older than 20 & $\begin{array}{c}0.0492^{* * *} \\
{[0.0103]}\end{array}$ & $\begin{array}{c}0.0177^{* * *} \\
{[0.0065]}\end{array}$ & $\begin{array}{c}0.3608^{* *} \\
{[0.1441]}\end{array}$ \\
\hline 4. Highly women $(>50 \%)$ & $\begin{array}{c}0.0589^{* * *} \\
{[0.0165]}\end{array}$ & $\begin{array}{l}0.0223^{*} \\
{[0.0123]}\end{array}$ & $\begin{array}{l}0.3782^{*} \\
{[0.2159]}\end{array}$ \\
\hline $\begin{array}{l}\text { 5. Highly technical } \\
\text { firm }(>15 \%)\end{array}$ & $\begin{array}{c}0.0573^{* * *} \\
{[0.0140]}\end{array}$ & $\begin{array}{c}0.0323^{* * *} \\
{[0.0118]}\end{array}$ & $\begin{array}{c}0.5624^{* *} \\
{[0.2189]}\end{array}$ \\
\hline \multicolumn{4}{|l|}{ Panel B. Age instrument } \\
\hline 1. Baseline & $\begin{array}{c}0.0450^{* * *} \\
{[0.0034]}\end{array}$ & $\begin{array}{c}0.0109^{* *} \\
{[0.0046]}\end{array}$ & $\begin{array}{c}0.2434^{* *} \\
{[0.1029]}\end{array}$ \\
\hline $\begin{array}{l}\text { 2. Over } 5 \text { years } \\
\text { of experience }\end{array}$ & $\begin{array}{c}0.0450^{* * *} \\
{[0.0034]}\end{array}$ & $\begin{array}{c}0.0108^{* *} \\
{[0.0046]}\end{array}$ & $\begin{array}{c}0.2400^{* *} \\
{[0.1026]}\end{array}$ \\
\hline 3. Older than 20 & $\begin{array}{c}0.0451^{* * *} \\
{[0.0034]}\end{array}$ & $\begin{array}{l}0.0087^{*} \\
{[0.0047]}\end{array}$ & $\begin{array}{l}0.1934^{*} \\
{[0.1052]}\end{array}$ \\
\hline 4. Highly women $(>50 \%)$ & $\begin{array}{c}0.0419^{* * *} \\
{[0.0052]}\end{array}$ & $\begin{array}{l}0.0159^{*} \\
{[0.0090]}\end{array}$ & $\begin{array}{l}0.3806^{*} \\
{[0.2191]}\end{array}$ \\
\hline $\begin{array}{l}\text { 5. Highly technical } \\
\text { firm }(>15 \%)\end{array}$ & $\begin{array}{c}0.0430^{* * *} \\
{[0.0062]}\end{array}$ & $\begin{array}{c}0.0185^{* *} \\
{[0.0080]}\end{array}$ & $\begin{array}{c}0.4297^{* *} \\
{[0.1915]}\end{array}$ \\
\hline
\end{tabular}

Notes: Specifications mirror the baseline specification described in Table 2. Clustered standard errors at the group level in brackets: Significant at $* 10 \%,{ }^{* *} 5 \%,{ }^{* * *} 1 \%$. 
Table 6-: Peer effects in the coworker's network with stronger and weaker ties, 2010-12.

\begin{tabular}{|c|c|c|c|c|}
\hline & $\begin{array}{c}\text { First Stage } \\
\text { (1) }\end{array}$ & $\begin{array}{c}\text { Reduced Form } \\
(2)\end{array}$ & $\begin{array}{c}\text { Second Stage } \\
(3)\end{array}$ & $\begin{array}{l}\mathrm{N} \\
(4)\end{array}$ \\
\hline \multicolumn{5}{|l|}{ A. Wage instrument } \\
\hline $\begin{array}{l}\text { 1. Former coworkers } \\
\text { (network at Dec 2007) }\end{array}$ & $\begin{array}{c}0.0316^{* * *} \\
{[0.0085]}\end{array}$ & $\begin{array}{l}0.0044^{*} \\
{[0.0025]}\end{array}$ & $\begin{array}{c}0.1378 \\
{[0.0847]}\end{array}$ & 777,566 \\
\hline $\begin{array}{l}\text { 2. Baseline } \\
\text { (network at Dec 2008) }\end{array}$ & $\begin{array}{c}0.0487^{* * *} \\
{[0.0104]}\end{array}$ & $\begin{array}{c}0.0145^{* *} \\
{[0.0067]}\end{array}$ & $\begin{array}{c}0.2971^{* *} \\
{[0.1459]}\end{array}$ & 166,871 \\
\hline $\begin{array}{l}\text { 3. Longer term coworkers } \\
\text { (network at Mar 2008-Dec 2008) }\end{array}$ & $\begin{array}{c}0.0646^{* * *} \\
{[0.0114]}\end{array}$ & $\begin{array}{c}0.0195^{* *} \\
{[0.0082]}\end{array}$ & $\begin{array}{c}0.3017^{* *} \\
{[0.1324]}\end{array}$ & 92,186 \\
\hline \multicolumn{5}{|l|}{ B. Age instrument } \\
\hline $\begin{array}{l}\text { 1. Former coworkers } \\
\text { (network at Dec 2007) }\end{array}$ & $\begin{array}{c}0.0393^{* * *} \\
{[0.0034]}\end{array}$ & $\begin{array}{l}0.0095^{*} \\
{[0.0056]}\end{array}$ & $\begin{array}{l}0.2411^{*} \\
{[0.1424]}\end{array}$ & 116,463 \\
\hline $\begin{array}{l}\text { 2. Baseline } \\
\text { (network at Dec 2008) }\end{array}$ & $\begin{array}{c}0.0450 * * * \\
{[0.0034]}\end{array}$ & $\begin{array}{c}0.0109^{* *} \\
{[0.0046]}\end{array}$ & $\begin{array}{c}0.2434^{* *} \\
{[0.1029]}\end{array}$ & 197,238 \\
\hline $\begin{array}{l}\text { 3. Longer term coworkers } \\
\text { (network at Mar 2008-Dec 2008) }\end{array}$ & $\begin{array}{c}0.0408^{* * *} \\
{[0.0038]}\end{array}$ & $\begin{array}{c}0.0110^{* *} \\
{[0.0051]}\end{array}$ & $\begin{array}{c}0.2696^{* *} \\
{[0.1266]}\end{array}$ & 112,751 \\
\hline
\end{tabular}

Notes: Specifications mirror the baseline specification described in Table 2. "Former coworkers" are those who were coworkers at December 2007 (one year and half before the beginning of the program). "Baseline" corresponds to our preferred network, constructed with coworkers in December 2008, and "Longer term coworkers" are those who worked at the same firm from March 2008 to December 2008. Clustered standard errors at the group level in brackets: Significant at * $10 \%, * * 5 \%,{ }^{* * *} 1 \%$. 


\section{Online Appendix}

Figure A1. : Density estimates of wages around cutoff $x_{0}$ for different dates.

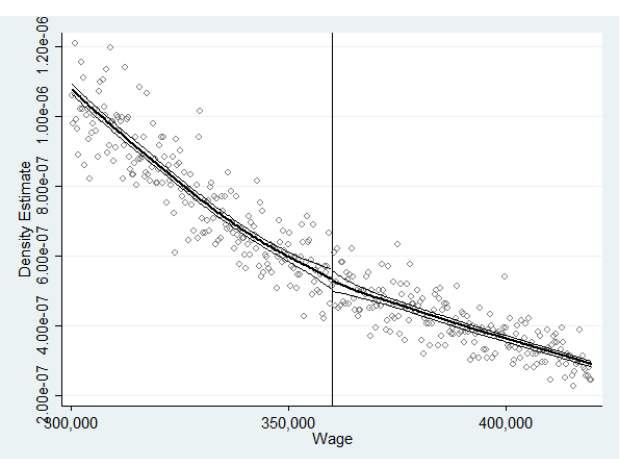

(a) March 2009

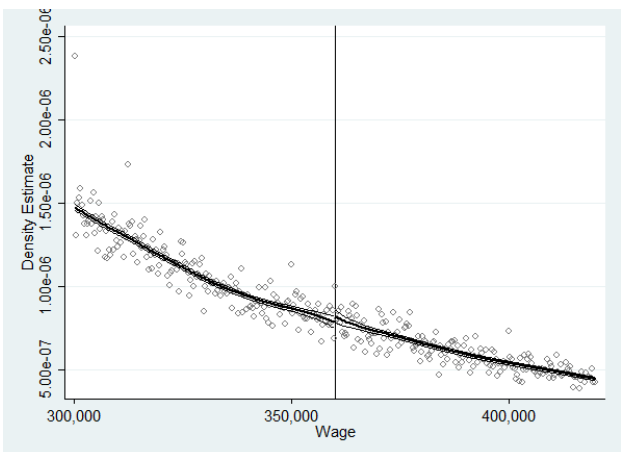

(c) December 2009

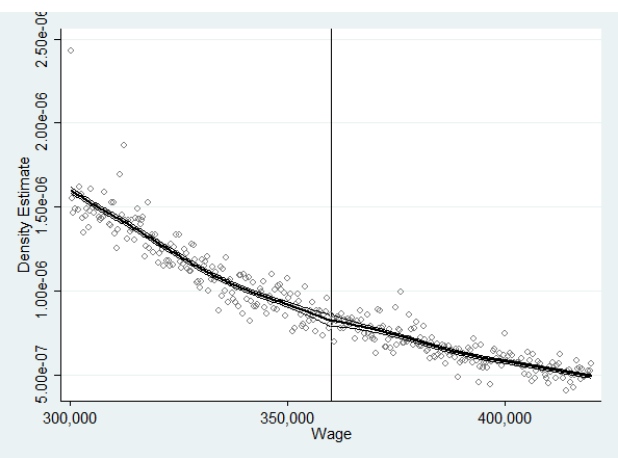

(e) September 2010

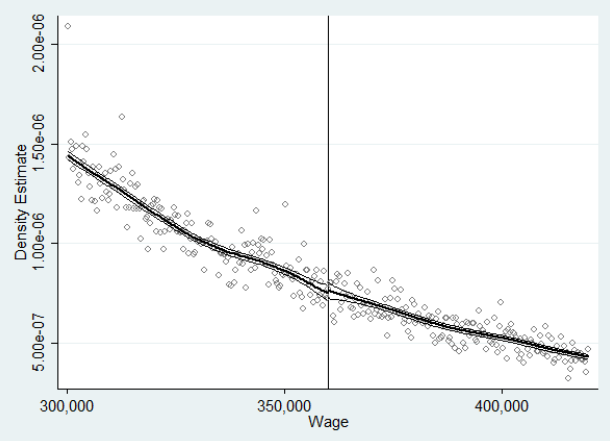

(b) September 2009

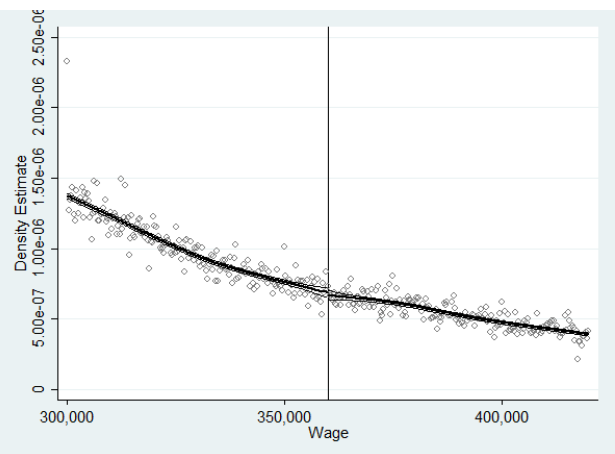

(d) March 2010

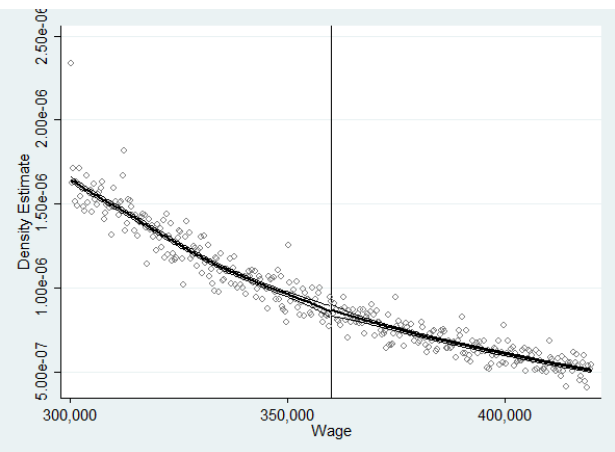

(f) December 2010

Notes: Each panel shows the density of wages for different dates. See Figure 3 for a description on construction. 
Figure A2. : Placebo estimates of the peer effects using the wage cutoff to construct the instrumental variable.

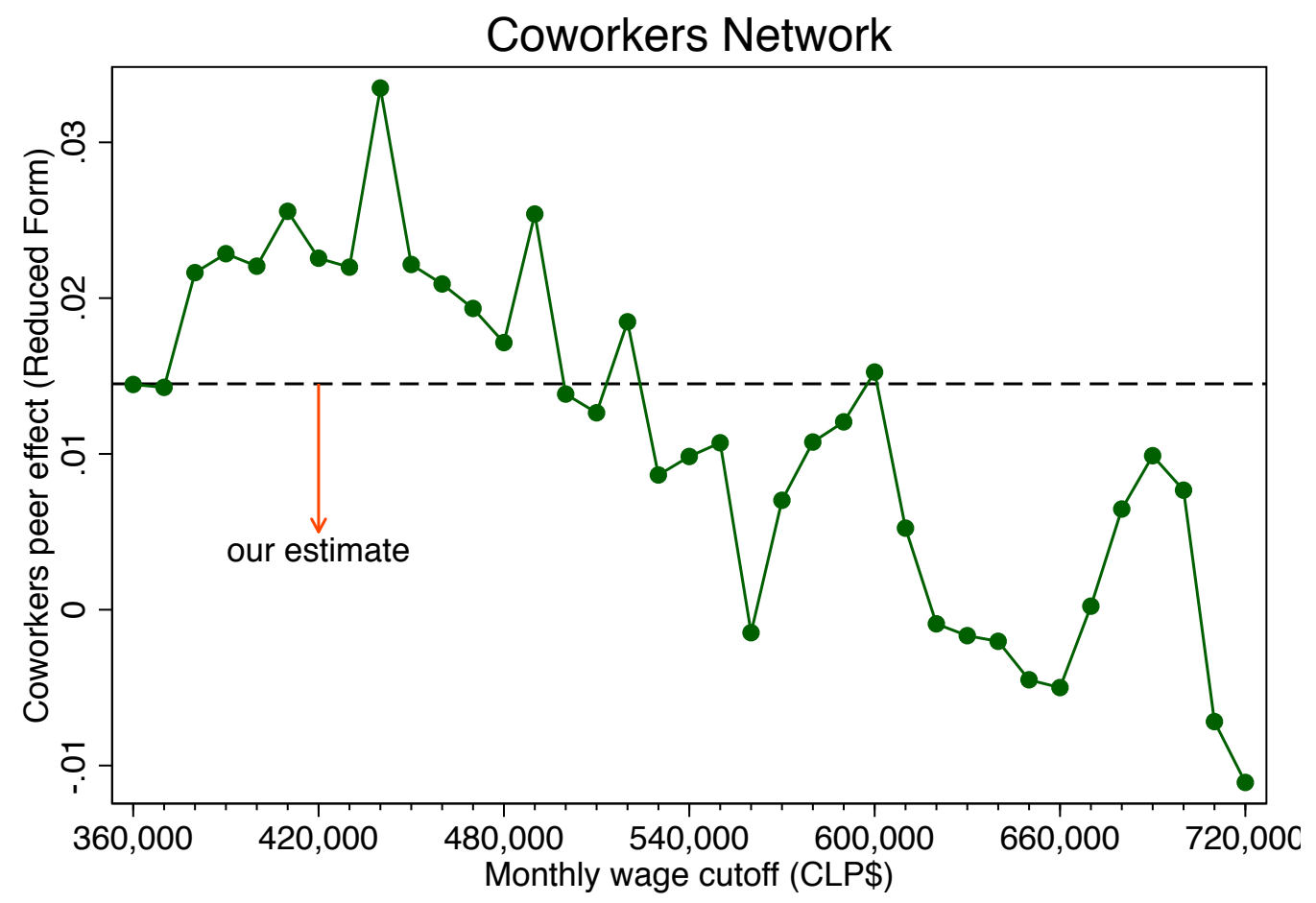

Notes: Each placebo estimate first assigns a window around the false wage cutoff, and then estimates a reduced form peer effect at the coworkers level. There are 37 estimates in this graph (from $\$ 360,000$ to $\$ 800,000$ ), where each estimate increases the false cutoff by $\$ 10,000$. The horizontal axis measures the cutoff wage and the vertical axis measures the coefficients. The horizontal line shows our baseline estimate of 0.0145 . 
Figure A3. : Placebo estimates of the peer effects using the age cutoff to construct the instrumental variable.

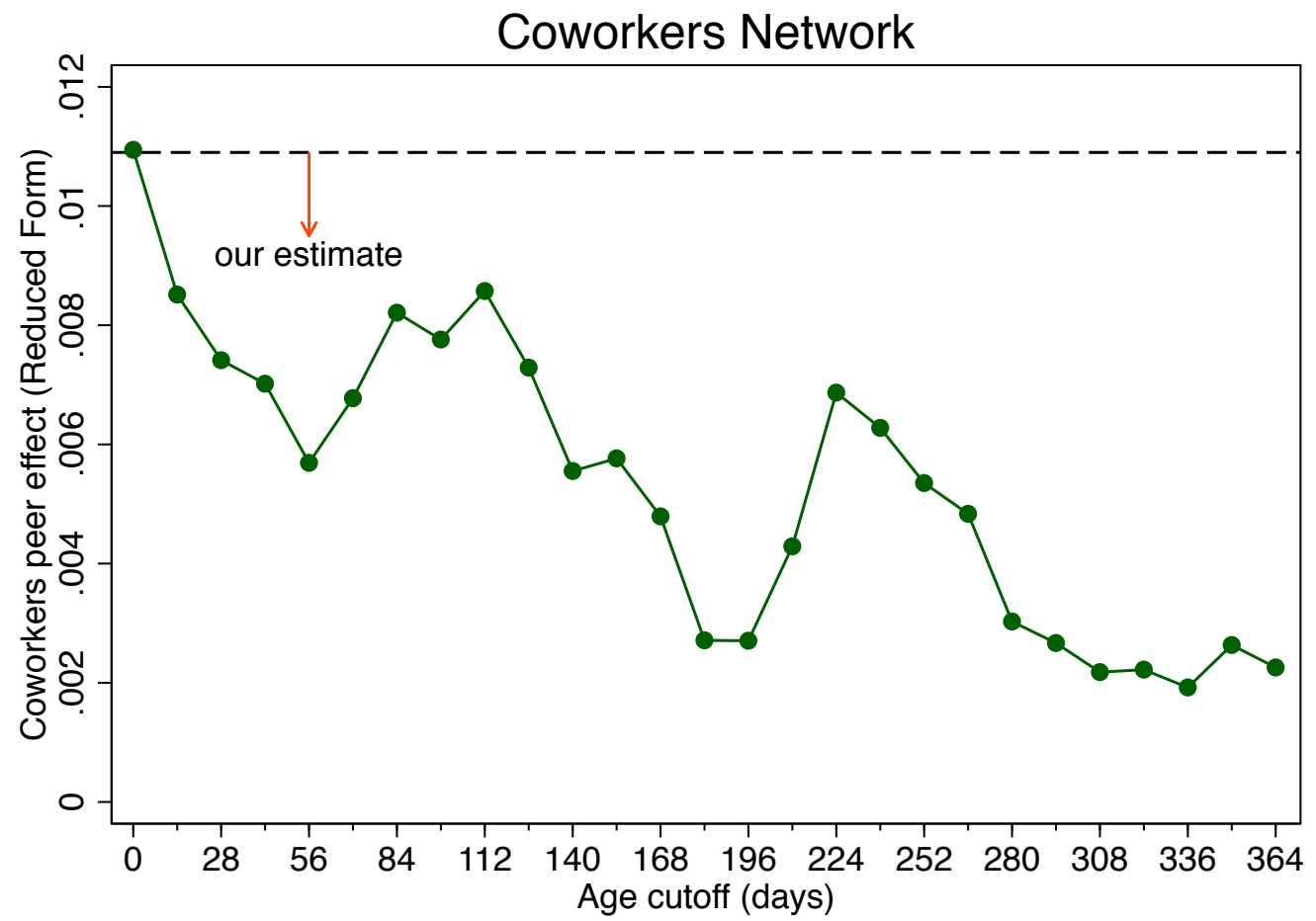

Notes: Each placebo estimate first assigns a window around the false age cutoff, and then estimates a reduced form peer effect at the coworkers level. There are 27 estimates in this graph (from 0 to 168), where each estimate increases the false cutoff by 7 days. The horizontal axis measures the cutoff age and the vertical axis measures the coefficients. The horizontal line shows our estimate of 0.0109. Standard errors clustered at the firm level. 
Table A1—: Descriptive statistics, full sample

\begin{tabular}{lcc}
\hline & Full Sample of Workers \\
& Mean & S.D. \\
& $(1)$ & $(2)$ \\
\hline Panel A: Individual Characteristics (Dec 2008) & 22.27 & 2.15 \\
Age & 0.37 & 0.48 \\
Women (\%) & $9,013.35$ & $3,731.36$ \\
Vulnerability score & 11.44 & 2.31 \\
Years of education & 8.23 & 3.58 \\
Months working during last year & 197.85 & 108.70 \\
Monthly wage (in thousands of CLP\$) & 0.59 & 0.49 \\
Eligible & 0.09 & 0.29 \\
Received YES during 2009 & 394,668 & \\
Observations & & \\
& & \\
Panel B: Group Characteristics & & \\
Firms (Dec 2008) & 6.60 & 44.05 \\
Firm size & 0.57 & 5.31 \\
Number of workers with YES during 2009 & 82,158 & \\
Observations & & \\
Classes (12th grade in Dec 2008) & & \\
Class size & 99.71 & 86.03 \\
Students with YES during 2009 & 3.65 & 5.42 \\
Observations & 1,705 & \\
\hline
\end{tabular}

Notes: Panel A shows information at the individual level for all who were employed in December 2008. Panel B shows information at the firm and school level. 
Table A2-: Descriptive statistics for individuals and peers in three estimating samples.

\begin{tabular}{|c|c|c|c|c|c|c|}
\hline & \multicolumn{4}{|c|}{ WAGE INSTRUMENT } & \multirow{2}{*}{\multicolumn{2}{|c|}{$\begin{array}{c}\text { AGE INSTRUMENT } \\
\text { COWORKERS }\end{array}$}} \\
\hline & \multicolumn{2}{|c|}{ COWORKERS } & \multicolumn{2}{|c|}{ CLASSMATES } & & \\
\hline & $\begin{array}{l}\text { Mean } \\
(1)\end{array}$ & $\begin{array}{c}\text { S.D. } \\
(2)\end{array}$ & $\begin{array}{c}\text { Mean } \\
(3)\end{array}$ & $\begin{array}{r}\text { S.D. } \\
(4)\end{array}$ & $\begin{array}{c}\text { Mean } \\
(5)\end{array}$ & $\begin{array}{c}\text { S.D. } \\
(6)\end{array}$ \\
\hline \multicolumn{7}{|c|}{ Panel A. Individual Characteristics (type 2 individuals) } \\
\hline Age & 22.04 & 2.13 & 21.52 & 1.57 & 21.67 & 1.48 \\
\hline Women $(\%)$ & 0.39 & 0.49 & 0.43 & 0.50 & 0.37 & 0.48 \\
\hline Vulnerability score & $8,952.66$ & $3,734.47$ & $9,446.08$ & $3,713.97$ & $8,770.66$ & $3,722.06$ \\
\hline Years of education & 11.45 & 2.21 & 11.88 & 1.97 & 11.39 & 2.20 \\
\hline Months working during last year & 8.01 & 3.53 & 8.13 & 3.46 & 7.78 & 3.68 \\
\hline Monthly Wage (in thousand of CLP $\$$ ) & 176.44 & 64.22 & 173.58 & 61.40 & 185.33 & 98.15 \\
\hline Eligible & 0.63 & 0.48 & 0.63 & 0.48 & 0.70 & 0.46 \\
\hline Received YES during 2009 & 0.00 & 0.00 & 0.00 & 0.00 & 0.00 & 0.00 \\
\hline Observations & 166,871 & & 90,668 & & 197,238 & \\
\hline \multicolumn{7}{|c|}{ Panel B. Peers Characteristics (type 1 individuals) } \\
\hline Age & 23.10 & 1.93 & 21.88 & 1.50 & 25.00 & 0.48 \\
\hline Women $(\%)$ & 0.25 & 0.43 & 0.26 & 0.44 & 0.42 & 0.49 \\
\hline Vulnerability score & $9,896.99$ & $3,677.41$ & $9,870.01$ & $3,678.38$ & $7,368.20$ & $2,884.18$ \\
\hline Years of education & 11.85 & 2.18 & 12.03 & 1.77 & 11.36 & 2.44 \\
\hline Months working during last year & 10.40 & 2.64 & 10.32 & 2.69 & 8.87 & 3.35 \\
\hline Monthly Wage (in thousand of CLP \$) & 342.75 & 38.50 & 340.78 & 37.99 & 213.11 & 118.90 \\
\hline Eligible & 0.38 & 0.49 & 0.47 & 0.50 & 0.47 & 0.50 \\
\hline Received YES during 2009 & 0.06 & 0.24 & 0.09 & 0.29 & 0.02 & 0.14 \\
\hline Average group size & 3.79 & 10.78 & 4.81 & 5.61 & 3.34 & 11.19 \\
\hline Number of groups & 14,067 & & 4,838 & & 18,644 & \\
\hline
\end{tabular}

Notes: Panel A shows individual characteristics for three different estimating samples. Columns (1) and (2) show means and standard deviations for individuals with coworkers networks when using "wage" to construct the instrumental variable. Columns (3) and (4) show the same statistics as in (1) and (2) for individuals with classmate networks, when using "wage" to construct the instrumental variable as well. Columns (5) and (6) show statistics for individuals with coworkers networks when using the "age" to construct the instrumental variable. Panel B shows information of peers in the three estimating samples described above. 
Table A3-: OLS estimates for the effect of the instruments on covariates.

\begin{tabular}{|c|c|c|c|c|c|c|}
\hline & \multicolumn{4}{|c|}{ A. Wage Instrument } & \multirow{2}{*}{\multicolumn{2}{|c|}{$\begin{array}{c}\text { B. Age Instrument } \\
\text { Coworkers }\end{array}$}} \\
\hline & \multicolumn{2}{|c|}{ Coworkers } & \multicolumn{2}{|c|}{ Classmates } & & \\
\hline & $\begin{array}{c}\text { Coef. [SD] } \\
\text { (1) }\end{array}$ & $\begin{array}{c}\mathrm{N}\left(R^{2}\right) \\
(2) \\
\end{array}$ & $\begin{array}{c}\text { Coef. [SD] } \\
(3)\end{array}$ & $\begin{array}{c}\mathrm{N}\left(R^{2}\right) \\
(4)\end{array}$ & $\begin{array}{c}\text { Coef. [SD] } \\
(5)\end{array}$ & $\begin{array}{c}\mathrm{N}\left(R^{2}\right) \\
(6) \\
\end{array}$ \\
\hline 1. Age & $\begin{array}{c}-0.234^{* *} \\
{[0.119]}\end{array}$ & $\begin{array}{c}175,561 \\
(0.04)\end{array}$ & $\begin{array}{c}-0.120^{* * *} \\
{[0.036]}\end{array}$ & $\begin{array}{c}108,779 \\
(0.77)\end{array}$ & & \\
\hline 2. Years of Education & $\begin{array}{c}0.150 \\
{[0.293]}\end{array}$ & $\begin{array}{c}166,871 \\
(0.06)\end{array}$ & $\begin{array}{l}-0.097 \\
{[0.087]}\end{array}$ & $\begin{array}{c}102,412 \\
(0.09)\end{array}$ & $\begin{array}{c}0.189^{* * *} \\
{[0.069]}\end{array}$ & $\begin{array}{c}197,238 \\
(0.03)\end{array}$ \\
\hline 3. Peers has some college & $\begin{array}{l}-0.041 \\
{[0.026]}\end{array}$ & $\begin{array}{c}175,561 \\
(0.05)\end{array}$ & $\begin{array}{l}-0.021 \\
{[0.022]}\end{array}$ & $\begin{array}{c}108,779 \\
(0.07)\end{array}$ & $\begin{array}{l}-0.001 \\
{[0.006]}\end{array}$ & $\begin{array}{c}203,733 \\
(0.01)\end{array}$ \\
\hline 4. Vulnerability Score & $\begin{array}{l}-287.788 \\
{[190.513]}\end{array}$ & $\begin{array}{c}175,561 \\
(0.06)\end{array}$ & $\begin{array}{c}0.656 \\
{[166.528]}\end{array}$ & $\begin{array}{c}108,779 \\
(0.21)\end{array}$ & $\begin{array}{c}90.165 \\
{[60.639]}\end{array}$ & $\begin{array}{c}203,733 \\
(0.01)\end{array}$ \\
\hline $\begin{array}{l}\text { 5. Fraction of last } \\
12 \text { months working }\end{array}$ & $\begin{array}{l}-0.132 \\
{[0.174]}\end{array}$ & $\begin{array}{c}175,561 \\
(0.07)\end{array}$ & $\begin{array}{l}-0.028 \\
{[0.141]}\end{array}$ & $\begin{array}{c}108,779 \\
(0.31)\end{array}$ & $\begin{array}{l}-0.002 \\
{[0.007]}\end{array}$ & $\begin{array}{c}203,733 \\
(0.13)\end{array}$ \\
\hline $\begin{array}{l}6 \text {. Fraction of female } \\
\text { workers }\end{array}$ & $\begin{array}{c}0.011 \\
{[0.015]}\end{array}$ & $\begin{array}{c}175,561 \\
(0.30)\end{array}$ & $\begin{array}{l}-0.003 \\
{[0.007]}\end{array}$ & $\begin{array}{c}108,779 \\
(0.10)\end{array}$ & $\begin{array}{c}0.013 \\
{[0.010]}\end{array}$ & $\begin{array}{c}203,733 \\
(0.05)\end{array}$ \\
\hline 7. Firm size before SEJ & $\begin{array}{l}-35.113 \\
{[26.096]}\end{array}$ & $\begin{array}{c}175,561 \\
(0.06)\end{array}$ & $\begin{array}{l}6.748^{*} \\
{[3.982]}\end{array}$ & $\begin{array}{c}108,779 \\
(0.04)\end{array}$ & $\begin{array}{c}19.439 \\
{[24.644]}\end{array}$ & $\begin{array}{c}203,733 \\
(0.02)\end{array}$ \\
\hline 8. School size & $\begin{array}{l}-1.066 \\
{[0.747]}\end{array}$ & $\begin{array}{l}95,610 \\
(0.13)\end{array}$ & $\begin{array}{c}1.227 \\
{[2.599]}\end{array}$ & $\begin{array}{c}108,779 \\
(0.15)\end{array}$ & & \\
\hline
\end{tabular}

Notes: Regressions use the coworkers sample (columns 1, 2, 5, and 6) and the classmates sample (columns 3 and 4). Columns (1)-(4) shows the regression coefficients of characteristics on the wage instrument in two networks (coworkers and classmates), while columns (5) and (6) shows the regression coefficients associated to the age instrument. Additional covariates not shown in the table include individual age, age squared, sex, $\ln ($ wage $)$, years of education and vulnerability score. Clustered standard errors at the group level are in brackets and $R^{2}$ coefficients in parentheses. ${ }^{*}$ significant at $10 \%, * *$ significant at $5 \%, * * *$ significant at $1 \%$. 